Preprint version 07.20.2021. This paper may be revised prior to publication.

\title{
A Randomized Controlled Trial of a Smartphone-Based Well-Being Training in Public School System Employees During the COVID-19 Pandemic
}

Matthew J. Hirshberg ${ }^{1}$, Corrina Frye ${ }^{1}$, Cortland J. Dahl ${ }^{1,2}$, Kevin M. Riordan ${ }^{1,3}$, Nathan J. Vack ${ }^{1}$, Jane Sachs $^{1}$, Robin Goldman ${ }^{1}$, Richard J. Davidson ${ }^{1,2}$, Simon B. Goldberg ${ }^{1,3}$

1. Center for Healthy Minds, University of Wisconsin-Madison

2. Healthy Minds Innovations Inc.

3. Department of Counseling Psychology, University of Wisconsin-Madison

\section{Author Note}

Matthew J. Hirshberg (D) https://orcid.org/0000-0001-9070-1270

Corrina Frye $i$ https://orcid.org/0000-0001-6201-0798

Cortland J. Dahl (Dhttps://orcid.org/0000-0002-2994-115X

Kevin M. Riordan Đhttps://orcid.org/0000-0001-7282-6889

Nathan J. Vack (Dhttps://orcid.org/0000-0002-4417-4737

Robin Goldman (Dhttps://orcid.org/0000-0002-4957-2486

Richard J. Davidson (Dhttps://orcid.org/0000-0002-8506-4964

Simon B. Goldberg_(Dhttps://orcid.org/0000-0002-6888-0126

Richard J. Davidson is the founder, president, and serves on the board of directors for the non-profit organization, Healthy Minds Innovations, Inc. Cortland J. Dahl is the primary content developer of the Healthy Minds Program and a scientist at Healthy Minds Innovations, Inc. Matthew J. Hirshberg has been a paid consultant at Healthy Minds Innovations, Inc. for work 
unrelated to this research. Robin Goldman has been a paid consultant at Healthy Minds Innovations, Inc. for work unrelated to this research.

This study was supported by an award from the Chan Zuckerberg Initiative (DAF 2020218037 [5022]) to RJD \& SBG) a National Academy of Education / Spencer Foundation Postdoctoral Research Fellowship (MJH), National Center for Complementary and Integrative Health Grants K23AT010879 (SBG) and U24AT011289-01 (RJD), funding from the Wisconsin Center for Education Research and the University of Wisconsin Madison Graduate School through support from the Wisconsin Alumni Research Foundation (SBG), REDCap software licensing through the University of Wisconsin-Madison's Institute for Clinical and Translational Research, and by generous individual donations to the Center for Healthy Minds and the University of Wisconsin-Madison's School of Education. No donors, either anonymous or identified, have participated in the design, conduct, or reporting of research results in this manuscript.

The data and conclusions presented in this manuscript have not been presented previously orally, on poster, or in print. A preprint of this manuscript is available on PsyArXiv (10.31234/osf.io/hrvmu). All data and code involved in analyses presented in this paper are available by request.

Correspondence should be addressed to: Matthew J. Hirshberg, Center for Healthy Minds, 625 W. Washington Ave., Madison, WI 53703, phone: 608-262-0035, fax: 608-2654174, email: hirshberg@wisc.edu and Simon B. Goldberg, Department of Counseling Psychology, University of Wisconsin-Madison, 335 Education Building, 1000 Bascom Mall, Madison, Wisconsin, 53706, United States, phone: 608-265-8986, fax: 608-265-4174, email: sbgoldberg@wisc.edu 


\begin{abstract}
While the extraordinary pressures of the COVID-19 pandemic on student mental health have received considerable attention, less attention has been placed on educator well-being. School system employees play a vital role in society, and teacher levels of well-being are associated with the educational outcomes of young people. We extend extant research on the prevalence and correlates of educator distress during the pandemic by reporting on a pragmatic randomized wait-list controlled trial $(N=662 ; 64 \%$ teachers $)$ of an innovative mental health promotion strategy implemented during the pandemic; a free four-week smartphone-based meditation app designed to train key constituents of well-being (Healthy Minds Program; HMP). Following our preregistered analysis plan and consistent with hypotheses, assignment to the HMP predicted significantly larger reductions in psychological distress, our primary outcome, at postintervention (Cohen's $d=-0.52,95 \%$ confidence interval $[-0.68,-0.37], p<.001$ ) and at the threemonth follow-up $(d=-0.33[-0.48,-0.18], p<.001)$. Also consistent with hypotheses, we observed similar indications of immediate and sustained benefit following the HMP on all six preregistered secondary outcomes selected to tap skills targeted in the app (e.g., perseverative thinking, social connection, well-being; absolute $d s=0.19-0.42$, all $p \mathrm{~s}<.031$ corrected except mindful action at follow-up). We found no evidence for elevated adverse events and the HMP was equally effective among participants with elevated baseline anxiety and depressive symptoms. These data suggest that the HMP may be an effective and scalable approach to supporting the mental health and well-being of teachers and other school system employees, with implications for employee retention and performance, and student outcomes.

Keywords: School system employees, COVID-19, mental health, mobile health, meditation
\end{abstract}




\section{Educational Impact and Implications Statement}

Although teachers and other school system employees play a vital role in society and have reported high levels of distress during the COVID-19 pandemic, relatively little attention has been placed on promoting their mental health and well-being. In a randomized trial of 662 Wisconsin school system employees (64.4\% teachers) conducted during the pandemic, we report that a four-week smartphone-based meditation app significantly reduced psychological distress and improved well-being, while also strengthening key skills underlying well-being (e.g., cognitive defusion, social connection) immediately following the intervention and three-months after it. Mobile meditation-based interventions may be an effective and scalable approach to supporting the mental health and well-being of teachers and other school system employees, with implications for several critical challenges facing educational systems, including employee retention and performance, and the relationship of these to student outcomes. 


\section{A Randomized Controlled Trial of a Smartphone-Based Well-Being Training in Public School System Employees During the COVID-19 Pandemic}

The SARS-CoV-2 (COVID-19) pandemic declared by the World Health Organization (WHO) in March 2020 has presented public health challenges unprecedented in recent history. The risks posed by infection are compounded by the impacts on individual and collective mental health and well-being, financial insecurity, and disruptions to critical societal institutions such as schools. In the United States, more than 6.7 million public school employees are charged with educating over 56 million pre-K $-12^{\text {th }}$ grade students (US Department of Education, 2018). Many teachers, instructional staff, building staff, and students have not physically entered a classroom since the declaration of the pandemic (U.S. Department of Education, 2021). The long-term deleterious effects of these radical changes to students' lives and the importance of supporting student mental health have garnered considerable attention (Holmes et al., 2020; Orben et al., 2020). Much less attention has been paid to the challenges faced by school system employees and the importance of supporting their mental health and well-being.

Overlooking the mental health and well-being of school system employees has important societal and educational implications. As in other professions, educator well-being and socialemotional skill promote effectiveness (Hanushek, 2011; Jennings \& Greenberg, 2009; Knudsen et al., 2006). In particular, higher teacher well-being and social-emotional skill has been associated with improved instruction and student outcomes (Braun et al., 2019; Jennings \& Greenberg, 2009; Klusmann et al., 2008, 2016, 2016; Zee \& Koomen, 2016). Conversely, higher levels of stress and dissatisfaction are associated with early career attrition from teaching and school administrative positions (Boyce \& Bowers, 2016; Hancock \& Scherff, 2010; Ryan et al., 2017). Students in schools with higher staff turnover and lower staff continuity have poorer 
educational achievement (Ronfeldt et al., 2013). Employees in low resource schools typically report higher levels of stress and leave at higher rates (Sorensen \& Ladd, 2020). Thus, to the extent that reducing employee distress positively affects turnover and increases staff stability and effectiveness, promoting and sustaining the well-being of school system employees is also an issue of equitable educational opportunities for students.

School system employees comprise a range of employment categories, from food service, building management, and nurses, to teachers, clerical staff, and school and district level administrators. Each plays an important role in supporting an educational system and the student outcomes that system generates. Reports from the Economic Policy Institute suggest that concerns about health safety upon returning to school, job insecurity for many categories of school system employees (e.g., building management staff, food service, transportation, and after school care), as well as the typical stresses of these professions have led to substantial levels of early retirement or career change (Garcia \& Weiss, 2020). For example, Garcia and Weiss (2019) estimate a shortage of over 100,000 teachers in American schools in the coming year. If upon returning to school, students are met with shortages of experienced and qualified staff, or staff that are highly stressed and therefore less effective, there is the potential that negative impacts on learning will continue after the acute COVID-19 public health crisis has abated.

The psychological impacts of the pandemic represent an emerging public health crisis (Holmes et al., 2020). Compared to pre-pandemic levels, rates of moderately severe and severe depressive symptoms in American adults have increased by approximately $400 \%$ and $500 \%$, respectively (Ettman et al., 2020). Available evidence suggest that teacher mental health is also suffering as a result of the pandemic (Markowitz et al., 2020). Pandemic-related decrements in mental health likely afflict low-income individuals and families and those with more COVID-19 
stressors to a greater extent (Ettman et al., 2020). Although teaching has been professionalized, in many states teachers still do not earn enough to achieve housing or food security, yet they earn considerably more than many other school system employees (Markowitz et al., 2020). The return to in-person instruction presents a variety of COVID-19 related risks and stressors, including the potential of infection if proper mitigation strategies are not implemented and enforced (García \& Weiss, 2019; Markowitz et al., 2020). Teachers and other school system employees therefore fit many of the criteria for elevated deleterious mental health effects resulting from the pandemic. There is an urgent need to provide school system employees with acceptable, accessible, and scalable (e.g., low-cost) strategies to reduce distress and promote well-being.

\section{Meditation Interventions for Mental Health and Well-Being}

A growing body of evidence demonstrates the benefits that meditation practice can have on psychological distress and well-being (Davidson \& McEwen, 2012; Goldberg et al., 2018; Goldberg, Riordan, et al., 2021; Goyal et al., 2014; Lindsay et al., 2019), with little evidence that moderate exposure to meditation potentiates harm (Galante et al., 2018; Hirshberg, Goldberg, et al., 2020). Thus far, research has focused primarily on mindfulness and connection styles of meditation practice (Dahl et al., 2020). Mindfulness is commonly defined as paying attention, on purpose, to present moment experience with an attitude of acceptance (Kabat-Zinn, 2013). A mindfulness meditation practice may involve attending to the sensations of the breath while relating to other experiences, including thoughts and emotional reactions, with an attitude of curiosity and acceptance. Connection practices are designed to strengthen prosocial qualities such as gratitude, feelings of affiliation, empathy, and compassion. An appreciation practice in which one intentionally notices positive qualities about other people to foster an attitude of 
friendliness and warmth is one example of a connection style practice (Dahl et al., 2020).

Results from research on mindfulness and connection interventions with educators mirror findings from other populations, showing improvements in teaching quality, stress, anxiety, depression, and indices of well-being following training (Hirshberg, Flook, et al., 2020; Jennings et al., 2017; Roeser et al., 2013). While promising, the quality of much of this evidence is weak (Klingbeil \& Renshaw, 2018). There are relatively few randomized controlled trials (RCT), sample sizes are typically small (i.e., the largest teacher RCT to date is N=224; Jennings et al., 2017), follow-up assessments are rare, and preregistration of study protocols, hypotheses, and methods is uncommon. In addition, no research has examined the impact of meditation interventions during the stress of the COVID-19 pandemic in school system employees.

This study addresses many of the limitations of extant research on meditation-based interventions with educators. Most research during the COVID-19 pandemic has examined the prevalence and correlates of teacher mental health and well-being (e.g., Alves et al., 2021; Ozamiz-Etxebarria et al., 2021). To our knowledge, the present study is the largest RCT of a meditation intervention with teachers or school system employees before or during the COVID19 pandemic ( $N=662$; teachers $n=426$ ). In addition, we preregistered the study design, methods, and hypotheses, conducted data analysis blind to condition assignment (i.e., the key to the assignment variable was disclosed after data analysis), include a three-month follow-up assessment, and evaluate an innovative, scalable, and accessible smartphone-based intervention.

\section{Theories of Change in Meditation Interventions}

Multiple theoretical models have been proposed to explain the processes by which meditation interventions produce salutary effects (Dahl et al., 2020; Lindsay \& Creswell, 2017; Vago \& Silbersweig, 2012). Although they vary in emphasis, there is consensus that the 
development of procedural skill in attentional and affective regulatory processes through repeated practice are critical mechanisms of benefit. For example, Vago and Silbersweig (2012) propose that meditation practice strengthens meta-awareness (i.e., the ability to be aware of internal processes of thoughts, emotions, sensations, and reactions to these) and the ability to modulate one's reactions to experience (i.e., self-regulation), while promoting prosocial dispositions. Lindsay and Creswell (2017) focused their theoretical model more narrowly on mindfulness practice, proposing the Monitor and Accept Theory. According to this theory, mindfulness practice builds attentional capacity that allows greater monitoring of on-going experience, but this may result in increased reactivity. Thus, the second active ingredient in mindfulness training according to Lindsay and Creswell (2017) is acceptance, operationalized as the mental attitude of receptivity, openness, or nonreactivity to experience (i.e., thoughts, sensations, emotions).

Dahl, Wilson-Mendenhall, and Davidson (2020) propose four pillars of well-being that can be strengthened through meditation training: awareness, connection, insight, and purpose (ACIP). Consistent with the previously reviewed models, awareness comprises attention and meta-awareness skills. Similar to Vago and Silbersweig's (2012) model, the connection pillar emphasizes prosocial attitudes and dispositions (e.g., gratitude, kindness). Dahl and colleagues (Dahl et al., 2015, 2020) expand the emphases on mindfulness and connection practices by introducing a richer taxonomy of meditation techniques, including forms of practice intended to produce insight into the structure of self-beliefs and identity (i.e., insight), and forms of practice aimed at clarifying one's values and purpose in daily life (i.e., purpose). They then review evidence that insight and purpose skills are associated with specific aspects of well-being (Dahl et al., 2020). 


\section{Mobile Health Meditation Interventions}

Meditation interventions have traditionally been conducted in-person, in group settings. In addition to limiting scalability, infection risks during the pandemic in most cases precluded this structure of treatment. Optimism surrounding the development of technology-mediated interventions, including meditation interventions, has grown (Linardon, 2019). Mobile health (mHealth) interventions comprise health interventions and monitoring systems mediated by technology and delivered outside of healthcare provider facilities (e.g., smartphone apps, webbased interventions; Park, 2016). Less bound by physical constraints, in theory mHealth interventions could be accessed at scale and for substantially lower cost than in-person alternatives. Research on mHealth meditation interventions suggest benefits similar to in-person interventions (Linardon, 2019). For example, a study of a web-based version of MindfulnessBased Cognitive Therapy, a first-line treatment for depressive relapse prevention, found significant reductions in anxiety and depressive symptoms, higher remission rates, and higher quality of life following the treatment and up to 15-months later compared to usual care controls who received antidepressants and access to psychotherapy (Segal et al., 2020).

The Healthy Minds Program (HMP) smartphone-based meditation intervention was constructed around the awareness, connection, insight, and purpose (ACIP) model of well-being proposed by Dahl and colleagues (2020). The full HMP app is a year-long intervention, with three-months of content for each of the ACIP pillars. Just as the ACIP framework extended theorizing on the mechanisms underlying meditation's benefits by including insight and purpose, the HMP extends current secular meditation training regimens, in-person and mHealth, beyond mindfulness and connection styles of practice by including insight and purpose practices that have not been widely utilized in secular meditation interventions or in research (Dahl et al., 
2015; 2020). HMP content as well as app design was refined through multiple user experience studies, including with school system employees, a highly diverse sample of college students, and general population adults. In addition, the architecture of the app is designed to be highly adaptable for research. For example, HMP duration and content can be easily modified. In consideration of the high levels of stress reported by school system employees, heightened by the pandemic, we implemented a four-week version of the HMP (one-week of content per ACIP pillar). Compared to programs like mindfulness-based stress reduction (Kabat-Zinn, 1982) that require hours of participant time over multiple months, the HMP asks participants for a modest investment of time of only minutes a day.

The one prior trial involving elements of the HMP examined the impact of two 8-week HMP iterations. In a three-arm RCT, both active arms involved four weeks of HMP awareness training. In one arm this was followed by four weeks of HMP connection training and in the other, four weeks of HMP insight training (Masked for review). Compared to the wait-list control group (WLC), after relatively low doses of meditation compared to in-person interventions, both HMP arms produced significant reductions in psychological distress and increases in mindfulness and social connection with no differences between the two (Masked for review). No prior study has examined the impact of training in all four ACIP domains. Despite the acute need to support school system employee well-being, the logistical challenge of inperson interventions during a global pandemic, and the promise of mHealth meditation interventions, we are not aware of any research on mHealth meditation interventions with this population.

\section{Theory of Positive Change Through Healthy Minds Program Training}

We structure our theory of change (Figure 1) around the training-based model of well- 
being proposed by Dahl and colleagues (2020). Dahl et al. (2020) review psychological and neuroscientific evidence that each of the four ACIP pillars are key constituents of well-being, that the skills circumscribed within each pillar demonstrate plasticity (i.e., can change), and that this plasticity can be harnessed through intentional practice. As previously noted, the full HMP and the four-week HMP used in this research were designed around this ACIP training-based model of change. Following this model, we preregistered hypotheses that training in awareness will increase awareness skills (e.g., mindfulness, meta-awareness), and similarly, training in connection and insight, will increase these respective skills (e.g., social connection, the ability to be aware of but not fused with thoughts, sensations, and emotions). Because of the short duration of the present intervention (4-weeks), we did not preregister predicted improvements in purpose (i.e., clarity regarding one's values) following the HMP training. As each ACIP domain and the skills within them are associated with increased well-being, we expected that strengthening ACIP skills would predict durable improvements in mental health and well-being.

\section{\{INSERT Figure 1. ABOUT HERE\}}

Prior research on mediation with teachers often cites Folkman and Lazarus' transactional model of stress and coping (Folkman \& Lazarus, 1988; Lazarus \& Folkman, 1984) to explain program benefits (e.g., Crain et al., 2017; Roeser et al., 2013). According to the transactional model (Folkman \& Lazarus, 1984), first order appraisals consist of a determination as to whether a situation has relevance to one's well-being (e.g., potentially stressful or harmful). Secondary appraisals comprise an evaluation of possible coping strategies to adjust to the situation. For example, an individual might evaluate the potential benefit of avoiding, escaping from, engaging with, or accepting current experience. Coping proceeds from this second order appraisal process and reflects the cognitions and behaviors employed in an attempt to adapt to circumstances. 
While we agree with prior theorizing that meditation training positively impacts stress and coping through changes in secondary appraisal and coping processes (e.g., acceptance; Crain et al., 2017; Lindsay \& Creswell, 2017), it is also possible that by strengthening awareness (e.g., as in mindfulness-based interventions) in addition to connection, insight, and purpose skills primary appraisal processes may be affected. For example, HMP connection practices might help participants reinterpret a past painful interaction by focusing on the challenges the other person was experiencing that led them to act hurtfully. This shift in perspective may alter the way a future experience is understood. For example, a difficult behavior may be perceived as an indication of that person's suffering rather than as a personal affront. HMP purpose practices also involve shifting attitudes toward, for instance, mundane activities of daily life that are routine at best or potentially irritating (e.g., folding the laundry, washing dishes). Using dishwashing or laundry folding as an opportunity to transform a labor into a generator of appreciation for what one has (e.g., "how lucky, look at all of these clothes!") or kindness (i.e., toward the people whose dishes one is washing), might also transform the primary appraisal of that situation from potentially stressful to potentially rewarding, thereby eliminating the need for secondary appraisal and coping processes. Strengthening ACIP skills may therefore reduce psychological distress and increase well-being by supporting the selection of adaptive secondary appraisal processes and cognitive and behavioral coping strategies (e.g., acceptance; Lindsay \& Creswell, 2017) or by altering primary appraisals such that fewer situations cause stress.

\section{Present Study}

The present study evaluated the impact of a four-week version of the Healthy Minds Program (HMP) in a pragmatic randomized wait-list controlled trial (RCT) of 662 Wisconsin school system employees during the COVID-19 pandemic. Participants were recruited between 
mid-June to late August 2020, randomly assigned following the completion of pre-test, assessed weekly during the four-week intervention period, assessed immediately following the end of the intervention period, and assessed a final time three-months after the intervention. Our preregistered primary outcome was psychological distress (i.e., z-score and then aggregate measures of stress, anxiety, and depression). Secondary outcomes include a measure of global well-being, perseverative thinking, and skills associated with each of the ACIP pillars: Awareness (mindful action); Connection (loneliness/social connection and self-compassion); Insight (cognitive defusion or the ability to be aware of but not fused with experience); and Purpose (meaning in life [not preregistered]).

We hypothesized that assignment to the HMP would decrease psychological distress (primary outcome) and increases awareness, connection, and insight skills, as well as increase overall well-being and reduce perseverative thinking (secondary outcomes) at post-test and three-month follow-up compared to the wait-list control (WLC) group. In addition, we conduct several exploratory analyses (i.e., not preregistered). Although we expect the HMP to enhance purpose skills over time, we did not preregister changes in purpose because of the short duration of the present HMP intervention (i.e., 4-weeks). Our first exploratory analysis examined change in presence of meaning in life, our measure of purpose. Second, to understand HMP effects among those with elevated psychological symptoms at baseline, we estimate models on the subsample reporting mild or greater and separately moderate or greater levels of anxiety and depressive symptoms at baseline. Third, the potential for adverse events is important but often unexamined in psychotherapeutic and meditation research (Britton et al., 2021; Dimidjian \& Hollon, 2010). We compare the prevalence of adverse events (operationalized as a categorical increase in symptoms using normative cutoffs on anxiety and depression measures; See 
Outcomes) between the HMP and control group. Finally, we examine whether treatment effects were moderated by employment category (teacher / other) or by the timing of the intervention (during the summer / into the new school year).

\section{Method}

\section{Study Design and Participants}

We conducted this RCT in the state of Wisconsin, USA during the COVID-19 pandemic and designed the study to coincide with structural elements of the school calendar. Recruitment and pre-testing began in mid-June 2020 and closed in late-August 2020, covering summer vacation when psychological distress is expected to naturally abate. In addition, summer 2020 corresponded to a lull in the intensity of the COVID-19 pandemic in Wisconsin. The four-week intervention phase occurred over summer vacation or during the first month of the new school year. The three-month follow-up assessment covered the first three to four months of the school year. Fall 2020 involved a rapidly worsening COVID-19 outbreak in Wisconsin. Most Wisconsin school systems remained in virtual instruction over the follow-up period.

Enrollment was open to any adult ( $\geq 18$ years of age) who worked for a Wisconsin school system serving pre-school to high school students (i.e., students aged 3 to 18 years old) and possessed a smartphone capable of downloading the HMP (Figure 2). We allowed all categories of school system employees to enroll with the understanding that every category of employment contributes to a functioning school system and with sensitivity to the importance during the pandemic of not restricting access to a potential mental health support. Participants were excluded if they had previously used the HMP (since Spring 2020 the HMP has been freely available to the public), had meditation retreat experience, had a regular meditation practice (i.e., at least once per week over the prior year), had been practicing meditation daily for the prior six 
months, or at prescreen reported severe depressive symptoms (i.e., $\geq 2$ standard deviations above population mean) on the National Institutes of Health's Patient-Reported Outcomes Measurement Information System Inventory (PROMIS Depression; Pilkonis et al., 2011). Full sample details are provided in Table 1. Participants reported as $87.98 \%$ female, $89.36 \%$ White, 4.3\% Hispanic, 4.07\% Black, 2.03\% Asian/Pacific Islander, and $<1.0 \%$ American Indian/Native Alaskan. The average age was 42.58 years old $(S D=10.67)$. The majority of participants were teachers $(64.35 \%)$.

Recruitment was conducted remotely through social media posting and email. Recruitment materials linked to a video in which the importance of the research and adhering to participation requirements was explained. In light of the pressures of the pandemic on mental health, we felt an ethical obligation to allow potential participants who felt that they could not wait to use the app (e.g., if assigned to wait-list) to access it immediately. Therefore, speakers in the video also recommended that such individuals should not enroll in the study and instead download and begin using the app.

After the video, participants indicated their interest in enrolling by completing the prescreen and providing their email address. They were notified that a follow-up email from the study team would arrive in two days. We implemented this staggered enrollment process because considerable non-adherence and attrition occurs in the earliest phases of mHealth research. By designing a two-day gap between initial interest and actual enrollment, we hoped to reduce study attrition. An automated email was then sent through a Research Electronic Data Capture (REDCap) system designed for this study to all eligible participants two days following prescreen. A link in the email led participants to the informed consent, where all study procedures, risks, and study compensation were described. Study materials and procedures were 
approved by the Masked for Review Institutional Review Board (2020-0533) on May 13, 2020. The study protocol was registered on June 11, 2020, at ClinicalTrials.gov (Masked for review), prior to participant recruitment. Study outcomes, hypotheses, and methods were preregistered on June 9, 2020 at the Open Science Foundation (Masked for review).

Simple random assignment $(1: 1)$ to either the four-week HMP or WLC occurred automatically within REDCap via a random number generator when participants completed the pre-test assessment on a rolling basis. Participants who did not complete the pre-test assessment were not randomly assigned and were not considered enrolled. Following pre-test and randomization, participants were not blind to study condition. Researchers were not involved in the randomization procedures (other than programming the procedure in REDCap) and became aware of assignment after the fact. Assessments were conducted remotely without experimenters (i.e., by participants on their computer or phone). Data analysis was conducted blind to condition assignment between January 18 and February 03, 2021 (i.e., no information about group sample sizes, HMP app data, or the code for the group assignment variable were provided to the researchers conducting analyses until after analyses were complete). All data and code used in the analyses presented in this manuscript are available upon request.

\section{Procedures}

After consent and completing pre-testing (T1), participants randomly assigned to the HMP were provided instructions on downloading a study-specific four-week version of the HMP. WLC assigned participants were told that the study team would provide instructions for downloading and using the HMP after the follow-up assessment. REDCap study management software was coded to send automated emails to participants who did not downloaded the app within a couple of days of the first email notification. Study team members followed up by email 
with participants who still had not downloaded the app after auto-reminders. One week after pretesting, HMP and WLC participants received another automated email from REDCap that included a link to week 1 assessments (T2). This procedure was followed for subsequent assessments at week 2 (T3), week 3 (T4), week 4 (T5, i.e., post-intervention), and three-month follow-up (T6). All outcomes were assessed at T1, T5, and T6. The primary outcome and a subset of secondary outcomes were also assessed at T2, T3, and T4 (see Outcomes).

REDCap was programmed to send reminder emails to participants who did not open an assessment link. T2 to T4 assessment links were open for one week. T5 and T6 links were left open for two weeks. Study team members monitored completion and followed up with participants by email if they (a) did not download the HMP by the time the T2 assessment was sent (if assigned to treatment) or (b) missed an assessment after REDCap reminders. As enrollment was rolling, each participant's timeline was based on their pre-test completion date. Participants, regardless of group, were compensated on the same graduated scale for a maximum of US \$150 for completing all assessments. Participants completing more assessments received greater compensation and completion of later assessments was more highly compensated (Supplemental materials Table S1).

\section{Intervention}

The full HMP is a year-long, comprehensive training based on a framework that highlights four pillars of well-being: awareness, connection, insight, and purpose (ACIP; Dahl et al., 2020). The awareness module focuses on attention skills (e.g., focused attention, mindfulness) and meta-awareness (awareness of thoughts, sensations, and emotions). The connection module emphasizes prosocial dispositions such as gratitude, empathy, compassion, and social connection. The insight module is intended to bring clarity about the nature of one's 
identity and experience (e.g., I am aware of this thought, but this thought does not define me). The purpose module aims to clarify one's values and motivations and to apply them in the activities of daily life. Well-being is conceptualized as a complex phenomenon that emerges from innate well-being capacities (e.g., attention regulation) and can be strengthened by bolstering these capacities through, among several strategies, skills-based meditation training. The program includes instruction in formal sitting meditation and in "active meditations" or informal practices that are designed to be integrated into one's regular daily routine. To give an example, one active meditation from the Purpose series involves listening to a guided meditation while doing a household chore and employing strategies to view the activity as an act of generosity or kindness.

The four-week Foundations course of the HMP studied here includes two introductory audio lessons and two introductory guided meditations (one sitting meditation and one active meditation), followed by one week of content for each pillar of well-being. Each week contains two brief podcast lessons ( 5 to 7 minutes each) with key insights from scientific research on well-being (i.e., psychoeducation), as well as practical examples illustrating how to strengthen the skills of each pillar in daily life. In addition, each week contains three guided meditations related to the respective pillar. Participants can choose between two guides (one maleidentifying, non-Latinx White guide and one female-identifying, Latinx guide), active or sitting practices, and practice length (5 to 30 minutes). In total, the intervention contains 10 lessons and 14 guided meditations.

\section{Outcomes}

Our primary outcome was psychological distress, operationalized as the aggregate of the 10-item NIH Perceived Stress Scale ( $\alpha=.86$; Cohen et al., 1983; Cyranowski et al., 2013) and the 
Patient Reported Outcomes Measurement Information Systems (PROMIS) Anxiety and Depression scales (adaptive 4 to 8 -items; Pilkonis et al., 2011). Although there may be important reasons to assess these outcomes separately, as a rule, clinical diagnoses of anxiety and depression are highly comorbid (Kalin, 2020). In addition, a single distress factor may underly all forms of psychopathology, and stress, anxiety, and depression all load on a single internalizing factor (Caspi et al., 2014).

The Perceived Stress Scale has demonstrated evidence of reliability and validity across diverse samples (Cohen et al., 1983; Cyranowski et al., 2013; Roberti et al., 2006). Items including "In the last month, how often have you felt that you were on top of things?" and "In the last month, how often have you felt difficulties were piling up so high that you could not overcome them?" are rated on a 1 (Never) to 5 (Very often) scale and summed, with higher scores representing higher levels of stress. PROMIS anxiety and depression scales ask participants to rate, on a 1 (Never) to 5 (Always) scale, how frequently in the past week they have experienced a series of anxiety or depressive symptoms, respectively. Items from the anxiety scale include "I felt uneasy" and "I felt nervous." Items from the depression scale include "I felt worthless" and "I felt unhappy."

The PROMIS scales were developed through item response theory on large, nationally representative samples $(n>20,000)$ that included subsamples with a variety of clinical conditions (Cella et al., 2010; Pilkonis et al., 2011). In initial and subsequent validation studies, the measures have demonstrated evidence for reliability and validity, including strong correlations with legacy measures (Cella et al., 2010; Pilkonis et al., 2011; Schalet et al., 2016). Subsequent research in diverse clinical and non-clinical samples has found additional evidence for validity as well as sensitivity to intervention (Bartlett et al., 2015; Schalet et al., 2016; Sunderland et al., 2018). We z-scored scale scores and then aggregated across the three measures to construct our 
psychological distress variable. For analyses of adverse events, PROMIS anxiety and depression measure T-scores, developed on a nationally representative subsample of the initial validation sample $(n=5,298)$, provide categorical symptom level cut-points based on the referent sample, with a population symptom mean of 50 and a standard deviation of 10 . Scores of $\geq 55<60$, $\geq 60<70$, and $\geq 70$ represent mild, moderate, and severe symptom levels, respectively.

Total average scores were computed for all secondary outcomes. Secondary outcomes were selected to assess key skills in each ACIP domain (hypothesis related to purpose was not preregistered because we assume changes in purpose occur over a longer timescale than the 4week intervention studied here), and global well-being. To assess skills of awareness, we used the 8-item Act with Awareness subscale of the Five Facet Mindfulness Questionnaire $(\alpha=.91$; Baer et al., 2008). Participants rate items including "I find it difficult to stay focused on what's happening in the present" and "When I do things, my mind wanders off and I'm easily distracted" on a 1 (Never or vary rarely true) to 5 (Very often or always true) scale. All items are reverse scored. Higher scores represent greater mindful action. Evidence for reliability and validity have been reported across a wide range of samples (e.g., Goldberg et al., 2015).

We assessed two connection skills - self-compassion and social connection/loneliness with the Self-Compassion Short Form (12-items; $\alpha=.86$; Raes et al., 2011) and the NIH Toolbox Loneliness Questionnaire (5-items; $\alpha=.90$; Cyranowski et al., 2013), respectively. For the SelfCompassion Short Form, participants rate on a 1 (Not at all true for me) to 5 (Very true for me) scale items such as "I try to see my failings as part of the human condition" and "I'm disapproving and judgmental about my own flaws and inadequacies (reverse).” Higher scores represent higher levels of self-compassion with scores ranging from 12 to 60 . There is substantial evidence for scale validity, including as a mediator of reduced distress in a mindfulness 
intervention with teachers (Roeser et al., 2013).

For the NIH Toolbox Loneliness Questionnaire, participants respond to prompts such as "In the past week, please describe how often..." "I feel that I am no longer close to anyone" or "I feel alone" on a 1 (Never) 5 (Always) scale. Scores range from 5-25 score range with higher scores reflecting greater loneliness. As with other PROMIS measures, initial validation included high correlations with legacy measures (Cella et al., 2010) and more recent work has observed additional evidence for reliability and validity in heterogenous samples (Cyranowski et al., 2013).

Insight skill was assessed with the Drexel Defusion Scale (10-items, $\alpha=.84$; Forman et al., 2012), a measure of cognitive defusion (i.e., awareness of internal experience without overidentification). The scale presents experiential vignettes and asks participants to rate how much defusion they would experience in each circumstance on a 0 (Not at all) to 5 (Very much) scale. For example, one item about "Thoughts of self" asks participants to "Imagine you are having a thought such as 'no one likes me.' To what extent would you normally be able to defuse from negative thoughts about yourself?" Scores range from 0 to 50 with higher scores represent greater defusion (i.e., greater insight). Evidence for scale reliability and validity have been observed in undergraduate students, general population adults, and clinical adult samples (Forman et al., 2012; Naragon-Gainey \& DeMarree, 2017).

Perseverative thinking or rumination was assessed with the Perseverative Thinking Questionnaire (15-items; $\alpha=.95$; Ehring et al., 2011), a measure of the "stickiness" of one's thoughts. Participants rate items such as "I think about many problems without solving any of them" and "My thoughts prevent me from focusing on other things" on a 0 (Never) to 4 (Almost always) scale. Higher scores reflect greater perseverative thinking. Evidence for scale validity 
includes research finding that greater perseverative thinking predicts later anxiety and depressive symptoms (Ehring et al., 2011; Ehring \& Ehlers, 2014; Nolen-Hoeksema et al., 2008).

Our final secondary outcome was a global measure of well-being, the World Health Organization-5 (WHO-5, 5-items; $\alpha=.85$; Bech, 2004), on which higher scores reflect greater overall well-being (score range 0-25). Participants rate items such as "I woke feeling fresh and rested" on a 0 (At no time) to 5 (All of the time) scale. The measure has shown evidence for validity in more than 30 languages as well as sensitivity to intervention (Topp et al., 2015).

As an exploratory outcome for purpose (i.e., not preregistered), we assessed the Meaning in Life Questionnaire Presence subscale (5-items, $\alpha=.91$; Steger et al., 2006). The Presence subscale assesses the presence of meaning and purpose in life through items such as "I understand my life's meaning." Participants rate items on a 1 (Absolutely untrue) to 7 (Absolutely true) scale (range 5-35) with higher scores representing greater presence of meaning and purpose. Evidence for validity has been observed in general population and clinical samples (Schulenberg et al., 2011; Steger et al., 2006).

As a preregistered covariate, we assessed at pre-test only the Social Desirable Response Set Five (5-items; $\alpha=.69$; Hays et al., 1989). Participants respond to items including "I sometimes try to get even rather than forgive and forget" on a 1 (Definitely true) to 5 (Definitely false) scale. Depending on the item, a 1 or 5 response is the 'extreme' response (i.e., a 1) and all other responses are coded as 0 . Scale scores range from 0 to 5 , with higher scores represent greater socially desirable responding.

\section{Sample Size}

As part of our preregistration, we conducted a prior sensitivity power analyses on the maximum allowable sample based on the funding secured at the time of preregistration $(N=400)$, 
noting in the preregistration that the sample would exceed $N=400$ if additional funding was secured. We assumed $43.4 \%$ attrition - the average attrition rate in mHealth research reported in a systematic review and meta-analysis (Linardon \& Fuller-Tyszkiewicz, 2020), for a completer sample of 226. Although we preregistered intention-to-treat analyses on all randomly assigned participants, we conducted the sensitivity power analysis on the predicted completer sample so that our power analysis estimates were conservative. Based on the above assumptions, the study preregistration was powered to detect a between group standardized mean difference of $\geq 0.38$, equivalent to meta-analytic estimates of the effect of mHealth mindfulness interventions on psychological distress (Linardon \& Fuller-Tyszkiewicz, 2020). Additional funding was secured prior to recruitment but after preregistration, resulting in a larger sample size than used in the power analysis.

\section{Statistical Analyses}

We first compute descriptive statistics on all outcomes and demographic variables, and examine variable distributions for normality (e.g., skewness, kurtosis). Following our preregistered analysis plan, before analyses we remove data of participants who failed more than $50 \%$ of attention check questions at an assessment (T1, T5, or T6; Supplemental materials Table S2 for items). We use independent sample Welch's t-tests (for continuous variables) and Chisquare tests (for categorical variables) to confirm that random assignment successfully resulted in group equivalence at baseline. We then compute the percent of missing data at each study endpoint (i.e., T5 and T6) by group, and compare group equivalence in missingness using logistic regressions in which missingness is regressed on the group assignment variable. In separate logistic regressions, we examine whether T1 levels of psychological distress predicts 
differential group attrition by regressing the interaction of $\mathrm{T} 1$ psychological distress and group assignment on T5 and T6 missingness.

Primary intention-to-treat analyses include all randomized participants except those failing attention checks. Results including those failing attention checks are reported in Supplemental materials Table S3 and are equivalent. We use linear-mixed effects models (time nested within participants) with maximum likelihood estimation to test our hypotheses of significant intervention group improvements on the primary (psychological distress) and all secondary outcomes (mindful action, self-compassion, loneliness, perseverative thinking, cognitive defusion, and well-being) at post-test (T5) and the three-month follow-up (T6). As preregistered, all models control for a dichotomous race variable (White/non-White), a dichotomous gender variable (male/female), and age. To help determine the best fit for modeling change over time, we plot outcomes over time by group using loess regression. We then quantitatively compare the Akaike Information Criterion (AIC) and Bayesian Information Criterion (BIC) of candidate models of linear change, loglinear change, polynomial change, and piecewise linear change in which change from T1 to T5 and T5 to T6 are modeled separately (e.g., see Segal et al., 2020). We use false discovery rate correction (FDR; Benjamini \& Hochberg, 1995) on secondary outcomes to ensure that the ratio of false positives to true positives does not exceed the two-tailed $p<0.05$ threshold for statistical significance. Feingold's (2009) model-based equivalent of Cohen's $d$ and its 95\% confidence interval (CI) are provided as an effect size estimate and its variability. We examine model assumptions (e.g., linearity, homogeneity of variance) using a simulation-based approach to produce scaled residuals that are then applied in diagnostics similar to those used in Ordinary Least Squares regression (e.g., qqplot, outlier estimation; Hartig, 2020). We conduct all statistical analyses in R (Team, 2014). 
Assuming data are Missing at Random (MAR), full-information maximum likelihood estimation provides unbiased estimates (Enders, 2001). To examine the robustness of model estimates to different missing not at random (MNAR) assumptions, we conduct pattern-mixture modeling (Iddrisu \& Gumedze, 2019; Leurent et al., 2018). Using multivariate imputation through chained equations that models the nested structure of the data, we impute 50 complete datasets under the MAR assumption. We examine imputed datasets for convergence and viability and then scale imputed values so that they are $10 \%$ and separately $20 \%$ worse than predicted based on the distribution of observed scores in their group (HMP/Control). The lower bound scaling factor (i.e., 10\%) is based on the minimal symptom change of clinical significance (Dworkin et al., 2008) making this sensitivity analysis a reasonable and rigorous assessment of the robustness of primary model effects observed under the MAR assumption (Goldberg, Bolt, et al., 2021). Finally, we reestimate linear mixed effects models on each imputed and scaled MNAR dataset separately and pool the results according to Rubin's rules (Rubin, 2004).

There was one deviation from our preregistered analysis plan. In place of the less robust sensitivity analysis we preregistered, we use the pattern-mixture modeling procedure just described.

We conducted four exploratory analyses (i.e., not preregistered). The first examines HMP effects on purpose. The second examines HMP effects on the subsample reporting slight or greater ( $\mathrm{T}$ score $\geq 55 ; 70^{\text {th }}$ percentile or higher), and separately moderate or greater ( $\mathrm{T}$ score $\geq 60$; $84^{\text {th }}$ percentile or higher) anxiety and depressive symptoms at pre-test. Third, to examine adverse events, we first categorize anxiety and depression scores separately at $\mathrm{T} 1$, $\mathrm{T} 5$, and $\mathrm{T} 6$ based on normative none-to-slight, mild, moderate, and severe symptoms (i.e., T-score $<55, \geq 55<60$, $\geq 60<70$, and $\geq 70$; Pilkonis et al., 2011). Using logistic regression models controlling for preregistered covariates, we estimate the difference between groups in the likelihood of a one 
category or greater worsening in symptoms (e.g., Jacobson \& Truax, 1991). Finally, we examine potential treatment effect moderation by occupational category (teacher/not teacher) and timing of intervention (during summer/into the new school year). Analysis code is publicly available (Masked for review). Study data is available by request.

\section{Results}

Between June 18 and August 28, 2020, 666 participants completed pre-testing and were randomly assigned ( $\mathrm{n}=320 \mathrm{WLC} / \mathrm{n}=346 \mathrm{HMP}$; Table 1$)$. Two participants from each group were removed from all analyses for failing more than $50 \%$ of attention checks at T1, T5 and T6 resulting in a final intention-to-treat sample of $N=662(\mathrm{n}=318 \mathrm{WLC} / \mathrm{n}=344 \mathrm{HMP})$. Data from six additional participants were removed at $\mathrm{T} 1$, and two each at $\mathrm{T} 5$ and $\mathrm{T} 6$ for failing attention checks at that timepoint (Figure 1). Consistent with intention-to-treat analysis, data from these participants at these timepoints were treated as missing and the participants were retained during analyses.

\section{\{INSERT Table 1 ABOUT HERE\} \\ \{INSERT Figure 2 ABOUT HERE\}}

Using independent group t-tests on continuous variables and Chi-square tests on categorical ones, we found no evidence for group differences at baseline (i.e., $p<.05$ on any assessed outcome or demographic feature (Table 1 and Supplemental materials Table S5). HMP group attrition $(\%[\mathrm{n}])$ was significantly higher than WLC at T5 (i.e., post-test; 18.6\% [64] vs. 9.12\% [29], $\mathrm{z}=-3.44, p<.001$ ) and T6 (i.e., 3-month follow-up; 18.0\% [62] vs. 8.81\% [28], $\mathrm{z}=-3.27$, $p=.001$; Supplemental materials Table S4). Overall, missing data were multivariate and a mix of monotonic and nonmonotonic (Liu, 2016). That is, most subject level missingness occurred across most or all variables at a given assessment, but there was variability at the subject level 
regarding whether missingness predicted later missingness. Attrition was unrelated to T1 distress levels, and the interaction between group and T1 distress did not significantly predict attrition. Across the sample, $79.9 \%(n=529)$ reported elevated anxiety and depressive symptoms at baseline $(\mathrm{T} \geq 55)$. A majority $(52.1 \%, n=345)$ of the sample reported moderate or higher anxiety and depressive symptoms at baseline $(\mathrm{T} \geq 60)$. Out of the 344 participants assigned to the HMP, $329(95.6 \%)$ downloaded the app, $271(78.78 \%)$ had one or more days of app use. The mean number of days of use was $10.88(\mathrm{SD}=9.08)$ and the mean number of minutes of practice was $127.93(\mathrm{SD}=130.63)$, with 89.05 minutes of sitting practice $(\mathrm{SD}=98.22)$ and 38.79 minutes of active practice $(\mathrm{SD}=68.37)$.

Piecewise linear mixed effects models fit the primary and secondary outcome data the best (Supplemental materials Table S6). For outcomes assessed at every timepoint (i.e., psychological distress, mindful action, loneliness, cognitive defusion, and purpose), T1 to T5 change modeled as a random slope and T5 to T6 change as a fixed effect fit the data best. For secondary outcomes assessed only at T1, T5, and T6 (i.e., self-compassion, perseverative thinking, and well-being), a fixed slope from T1 to T5 and from T5 to T6 fit the data best (i.e., random intercept model). Full descriptive statistics on each outcome at each timepoint by group are presented in Supplemental materials Table S6.

Consistent with our primary outcome hypothesis, the HMP group demonstrated significantly larger reductions in psychological distress over the intervention period compared to the WLC ( $d=-0.53$ CI [-0.69 to -0.38$], p<.001$; Figure 3$)$. Change over the follow-up was significantly different between the groups, favoring the WLC ( $d=0.22$ [0.07 to 0.37]). Consistent with our hypothesis, assignment to the HMP continued to predict significantly larger reductions 
in distress at T6 compared to the WLC $(d=-0.34[-0.49$ to -0.19$], p<.001)$. Effects were robust to pattern-mixture model sensitivity analyses (Supplemental materials Table S7).

\{INSERT Figure 3 ABOUT HERE\}

Consistent with preregistered secondary outcome hypotheses, over the intervention period, assignment to HMP predicted significant improvements compared to the WLC in mindful action $\left(d=0.21[0.06\right.$ to 0.36$\left.], p_{\mathrm{FDR}}=.001\right)$, self-compassion $(d=0.40[0.25$ to 0.55$]$, $\left.p_{\mathrm{FDR}}<.001\right)$, loneliness $\left(d=-0.34[-0.49\right.$ to -0.19$\left.], p_{\mathrm{FDR}}<.001\right)$, cognitive defusion $(d=0.40[0.25$ to $\left.0.56], p_{\mathrm{FDR}}<.001\right)$, perseverative thinking $(d=-0.35$ [-0.51 to -0.20$\left.], p_{\mathrm{FDR}}<.001\right)$, overall wellbeing $\left(d=0.42[0.27\right.$ to 0.58$\left.], p_{\mathrm{FDR}}<.001\right)$, and meaning in life (not preregistered, $d=0.28[0.13$, 0.43], $p_{F D R}<.001$; Figure 4). T5 to T6 change was significantly different between the groups only on self-compassion, favoring the WLC group $(d=-0.22[-0.37$ to -0.06$], p=.004$. Also consistent with preregistered secondary outcome hypotheses, all significant HMP group intervention period improvements persisted over the three-month follow-up (self-compassion $d=0.26$ [0.11 to 0.41$]$, $p_{\mathrm{FDR}}=.003$; loneliness $d=-0.32$ [-0.47 to -0.17$], p_{\mathrm{FDR}}=.002$; cognitive defusion $d=0.35$ [0.20 to $0.50], p_{\mathrm{FDR}}=.002$; perseverative thinking $d=-0.22$ [-0.37 to -0.07$], p_{\mathrm{FDR}}=.017$; well-being $d=0.34$ [0.19 to 0.49$], p_{\mathrm{FDR}}<0.001$; and meaning in life (not preregistered) $d=0.30$ [0.15 to 0.45$]$, $p_{\mathrm{FDR}}<0.001$ ) except for mindful action $d=0.14[-0.01$ to 0.29$], p_{\mathrm{FDR}}=.074$ (Figure 4 ).

All secondary outcome effects were robust in sensitivity analyses (i.e., $p<.05$ ) except mindful action at T5 (at 20\% worse than the MAR assumption) and T6 (at 10\% \& 20\% worse than the MAR assumption), perseverative thinking at T5 and 6 (at 20\% worse than the MAR assumption), and self-compassion at T6 (20\% worse than the MAR assumptions; Supplemental materials Table S7).

\{INSERT Figure 4 ABOUT HERE\} 


\section{Subsample Analyses}

Estimating piecewise linear mixed effects model on the subset of participants reporting mild or greater anxiety and depressive symptoms at pre-test ( $\geq 55$; HMP $n=276$, WLC $n=252$ ), the HMP group reported significantly larger distress reductions than WLC over the intervention period $(d=-0.60$ CI $[-0.78$ to -0.43$], p<.001)$. Compared to WLC, HMP group reductions were sustained over the three-month follow-up $(d=-0.37$ [-0.54 to -0.20$], p<.001)$. Restricting the sample further to participants with moderate or greater anxiety and depression at pre-test $(\mathrm{T} \geq 60$; HMP $n=181$, WLC $n=162$ ), the HMP group reported significantly greater distress reductions than WLC at T5 $(d=-0.60[-0.83$ to -0.37$], p<.001)$ that persisted over the three-month follow-up $(d=-0.36[-0.59$ to -0.13$], p<.001)$.

\section{Adverse Events}

Assignment to the HMP predicted significantly lower odds of experiencing increased anxiety symptoms at $\mathrm{T} 5$ (Odds ratio $(O R)=0.42[0.30$ to 0.60$], p<.001)$ with no difference in the odds of a categorical symptom increase in symptoms at T6 $(O R=0.78$ [0.56 to 1.10$], p=.143)$. Similarly, assignment to the HMP group predicted significantly lower odds of increased depressive symptoms at $\mathrm{T} 5(O R=0.65$ [0.45 to 0.93$], p=.020)$ with no difference in the odds of a categorical symptom increase in symptoms at T6 $(O R=0.82$ [0.57 to 1.18$], p=.278)$. In addition, we continued to find no evidence for increased prevalence of adverse events in the HMP group in sensitivity analyses (Supplemental materials Table S8).

\section{Moderation}

Employment (teacher/other) category did not moderate treatment effect on the primary or any secondary outcome (all $p s>.05$ uncorrected). Similarly, outcomes did not differ between participants who completed the entire intervention over the summer or finished the intervention 
during the new school year ( $p s>.05$ uncorrected).

\section{Discussion}

School system employees play a vital role in the functioning of society and in determining future social and economic outcomes (Hanushek, 2011). These data suggest that in the midst of a global pandemic, a four-week, self-guided meditation-based well-being training is acceptable to school system employees and has immediate small-to-moderate magnitude benefits on psychological distress (primary outcome) that persist for three-months following the intervention. In addition, assignment to the HMP predicted immediate small-to-moderate magnitude improvements in well-being skills (e.g. mindful action, self-compassion, cognitive defusion, social connectedness, presence of purpose and meaning), reductions in an antecedent to anxiety and depression (i.e., perseverative thinking), and increased overall well-being, all persisting three-months following the intervention except mindful action $\left(p_{F D R}=.076\right)$.

We conducted several preregistered and exploratory sensitivity analyses to examine the robustness of the observed effects. In addition to primary intention-to-treat analyses that included FDR error control on all secondary outcomes, assignment to the HMP continued to predict significant improvements on nearly all outcomes over the intervention and the follow-up period. It is also notable that HMP group benefits were as large or larger in analyses restricted to the subsample of participants with elevated anxiety and depressive symptoms at baseline.

The benefits of reducing psychological distress and enhancing well-being are self-evident and important. In the case of school system employees and particularly teachers who interact directly with and explain significant variability in student outcomes (Rivkin et al., 2005), the impacts of reducing distress and improving well-being extend to students, schools, and educational systems. As noted, a growing body of research demonstrates the relationship 
between teacher psychological functioning and instructional quality (Braun et al., 2019; Jennings et al., 2017; Jennings \& Greenberg, 2009), which in turn predicts student outcomes (Allen et al., 2011). In addition, teacher well-being is correlated with a more positive school climate. Positive school climate is associated with a host of benefits for students, including improved mental health, self-concept, absenteeism, and academic achievement (Thapa et al., 2013).

At the systems level, teacher and administrator stress and occupational dissatisfaction are predictors of leaving the profession (Boyce \& Bowers, 2016; Hancock \& Scherff, 2010; Ryan et al., 2017). High levels of school employee turnover negatively affect student outcomes (Ronfeldt et al., 2013) and place a significant economic burden on school systems in order to recruit and train new staff (Carroll, 2007). This burden is felt by all school systems, but because turnover is higher in low resource districts (Carver-Thomas \& Darling-Hammond, 2017; Sorensen \& Ladd, 2020), disadvantaged students are more likely to experience less effective teachers (Goldhaber et al., 2015) and low resource districts must expend more of their limited resources on hiring and training.

The links between teacher and other school system employee well-being, effectiveness, career longevity, and student and system outcomes are complex. Illuminating these links is a compelling warrant for continued research. In particular, most relevant extant research is correlational in nature. Experimental research is needed to identify causal chains among these phenomena, and once identified, use this knowledge to inform future policy decisions in areas ranging from hiring practices and certification to teacher education and professional development activities. For instance, a RCT conducted with undergraduate preservice teachers found that three-years after matriculating into the workforce, participants who were assigned to the meditation-based well-being training were about six times more likely to still be teaching 
(Masked for review), suggesting the meditation interventions during preservice teacher education may promote persistence in the profession.

Although the stress of a global pandemic is unique, there are many reasons that improving the mental health and well-being of teachers and other school system employees will remain highly relevant in a post-COVID world (Schonert-Reichl, 2019). Heightened educator stress was a concern before the pandemic (e.g., Kyriacou, 2001; Mitani, 2018). Many of the conditions that led to elevated stress have not changed. For the foreseeable future school system employees will continue to face threats related to COVID-19 variants and clusters of unvaccinated adults and students. Emergent stressors, for example the stress of increasingly common environmental crises related to climate change (e.g., wild fires, floods, drought), will challenge school system employee resilience as well (Cianconi et al., 2020).

A considerable body of evidence suggests that meditation-based programs promote mental health and well-being (e.g., Goldberg et al., 2018, 2021). If these interventions are part of the solution to supporting school system employee mental health and well-being, it is important that research also consider the potential for adverse events. This possibility is especially salient when thinking about widescale implementation of meditation programs as mandatory professional development, as they conceivably could be among school system employees. We find no evidence, including under MNAR assumptions, that assignment to the HMP resulted in increased adverse events; to the contrary, we find some evidence that in addition to reducing distress, the HMP may be preventative of increased distress over the four-week intervention period and at follow-up. For high stress professions such as teaching, educational administration, and other school system employment categories, the preventive potential of trainings like the 
HMP is an important area for future investigation made more so by the fact that these data were collected during the COVID-19 pandemic.

The overall pattern of results we observed is consistent with our theory of change, in which strengthening of key awareness, connection, insight, and purpose skills promotes durable improvements in mental health and well-being. As predicted, ACIP skills training through the HMP produced significant gains in all measured ACIP target skills. Also as predicted, mental health (i.e., psychological distress) and well-being improved following the intervention, with persistent effects at three-month follow-up. Although our data cannot establish that primary appraisal processes were affected by the HMP, the significant HMP group increases in social connection (i.e., decreases in loneliness) are noteworthy. The entire study was conducted during the COVID-19 pandemic. Follow-up occurred during a significant outbreak in Wisconsin. Thus, it seems reasonable to assume that the level of in-person interaction did not substantively change for participants during the study. HMP participants nevertheless reported significantly greater social connection, indicating a possible change in primary appraisals of life circumstance. That is, it is possible that social distancing came to be perceived as less isolating, resulting in fewer feelings of loneliness. Along with designing research to examine the degree to which unique features of the HMP (e.g., active practices) helped promote skills acquisition, exploration of possible alterations in primary appraisal processes is an important area for future investigation.

There are several strengths to this pragmatic trial. To our knowledge, this is the largest RCT of a meditation intervention of any kind (mobile or in-person) with school system employees, the first to examine intervention impacts during the COVID-19 pandemic, and the only to study a fully self-guided intervention. Scalability has been a limiting feature of in-person meditation interventions. The fully self-guided and remote delivery of the intervention along 
with its accessibility (it is free) substantially address these concerns. One final strength is the preregistration of primary and secondary outcomes, procedures, and analysis methods.

\section{Limitations}

There are a few important study limitations. First, without an active control condition, we cannot make inferences about the relative efficacy of the HMP against other bona fide programs or over and above non-specific factors such as expectancy. Comparative efficacy research is an important next step. There are strong theoretical reasons, supported by empirical results, to expect that the observed improvements in well-being skills, mental health, and well-being will translate to occupational improvements (Masked for review; Jennings et al., 2017; Wells \& Klocko, 2018). However, in part because of the inconsistency in schooling scenarios resulting from the pandemic, we did not assess measures specific to occupational stress, satisfaction, or performance. These outcomes represent another important area for future study. Although this sample is demographically representative of Wisconsin school system employees, the gender and race composition are fairly homogenous (i.e., predominately female, non-Latinx White), limiting our ability to generalize to states and school systems with more heterogenous employee pools (e.g., more male-identifying and/or person of color identifying). A final limitation is the reliance on self-reported outcomes which could enhance biases associated with unblinded group assignment (i.e., an open-label trial).

\section{Conclusion}

In conclusion, at a time of multiple urgent public health needs, an acceptable, accessible (i.e., freely available), scalable, and relatively brief meditation-based well-being training appears to support resilience during the COVID-19 pandemic amongst school system employees - a population that plays an essential role in the functioning of society. These results reinforce the 
potential of mHealth interventions to build resilience, support mental health, and improve overall well-being. These data warrant further research that explores the comparative efficacy of the HMP against other active interventions and expands outcomes to include objective health and job performance measures (e.g., health care utilization, absenteeism, metrics of performance). In addition, the HMP is well suited to deconstruction trials that have the potential to isolate the effects of specific elements of the training (e.g., awareness versus connection, insight versus purpose) and thereby support individualized and optimized interventions. 


\section{References}

Allen, J. P., Pianta, R. C., Gregory, A., Mikami, A. Y., \& Lun, J. (2011). An interaction-based approach to enhancing secondary school instruction and student achievement. Science, 333(6045), 1034-1037.

Alves, R., Lopes, T., \& Precioso, J. (2021). Teachers' well-being in times of Covid-19 pandemic: Factors that explain professional well-being. IJERI: International Journal of Educational Research and Innovation, 15, 203-217. https://doi.org/10.46661/ijeri.5120

Baer, R. A., Smith, G. T., Lykins, E., Button, D., Krietemeyer, J., Sauer, S., Walsh, E., Duggan, D., \& Williams, J. M. G. (2008). Construct Validity of the Five Facet Mindfulness Questionnaire in Meditating and Nonmeditating Samples. Assessment, 15(3), 329-342. https://doi.org/10.1177/1073191107313003

Bartlett, S. J., Orbai, A.-M., Duncan, T., DeLeon, E., Ruffing, V., Clegg-Smith, K., \& Bingham, C. O. (2015). Reliability and Validity of Selected PROMIS Measures in People with Rheumatoid Arthritis. PLOS ONE, 10(9), e0138543. https://doi.org/10.1371/journal.pone.0138543

Bech, P. (2004). Measuring the dimension of psychological general well-being by the WHO-5. Quality of Life Newsletter, 15-16.

Benjamini, Y., \& Hochberg, Y. (1995). Controlling the false discovery rate: A practical and powerful approach to multiple testing. Journal of the Royal Statistical Society. Series B (Methodological), 289-300.

Boyce, J., \& Bowers, A. J. (2016). Principal Turnover: Are There Different Types of Principals Who Move From or Leave Their Schools? A Latent Class Analysis of the 2007-2008 
Schools and Staffing Survey and the 2008-2009 Principal Follow-Up Survey. Leadership and Policy in Schools, 15(3), 237-272. https://doi.org/10.1080/15700763.2015.1047033

Braun, S. S., Roeser, R. W., Mashburn, A. J., \& Skinner, E. (2019). Middle School Teachers' Mindfulness, Occupational Health and Well-Being, and the Quality of Teacher-Student Interactions. Mindfulness, 10(2), 245-255. https://doi.org/10.1007/s12671-018-0968-2

Britton, W. B., Lindahl, J. R., Cooper, D. J., Canby, N. K., \& Palitsky, R. (2021). Defining and measuring meditation-related adverse effects in mindfulness-based programs. Clinical Psychological Science, 2167702621996340.

Carroll, T. (2007). Policy brief: The high cost of teacher turnover. National Commission on Teaching and America's Future.

Carver-Thomas, D., \& Darling-Hammond, L. (2017). Teacher turnover: Why it matters and what we can do about it. Palo Alto, CA: Learning Policy Institute.

Caspi, A., Houts, R. M., Belsky, D. W., Goldman-Mellor, S. J., Harrington, H., Israel, S., Meier, M. H., Ramrakha, S., Shalev, I., Poulton, R., \& Moffitt, T. E. (2014). The p Factor: One General Psychopathology Factor in the Structure of Psychiatric Disorders? Clinical Psychological Science : A Journal of the Association for Psychological Science, 2(2), 119137. https://doi.org/10.1177/2167702613497473

Cella, D., Riley, W., Stone, A., Rothrock, N., Reeve, B., Yount, S., Amtmann, D., Bode, R., Buysse, D., Choi, S., Cook, K., DeVellis, R., DeWalt, D., Fries, J. F., Gershon, R., Hahn, E. A., Lai, J.-S., Pilkonis, P., Revicki, D., ... Hays, R. (2010). The Patient-Reported Outcomes Measurement Information System (PROMIS) developed and tested its first wave of adult self-reported health outcome item banks: 2005-2008. Journal of Clinical Epidemiology, 63(11), 1179-1194. https://doi.org/10.1016/j.jclinepi.2010.04.011 
Cianconi, P., Betrò, S., \& Janiri, L. (2020). The Impact of Climate Change on Mental Health: A Systematic Descriptive Review. Frontiers in Psychiatry, 0. https://doi.org/10.3389/fpsyt.2020.00074

Cohen, S., Kamarck, T., \& Mermelstein, R. (1983). A global measure of perceived stress. Journal of Health and Social Behavior, 24(4), 385-396.

Crain, T. L., Schonert-Reichl, K. A., \& Roeser, R. W. (2017). Cultivating teacher mindfulness: Effects of a randomized controlled trial on work, home, and sleep outcomes. Journal of Occupational Health Psychology, 22(2), 138-152. https://doi.org/10.1037/ocp0000043

Cyranowski, J. M., Zill, N., Bode, R., Butt, Z., Kelly, M. A. R., Pilkonis, P. A., Salsman, J. M., \& Cella, D. (2013). Assessing Social Support, Companionship, and Distress: NIH Toolbox Adult Social Relationship Scales. Health Psychology: Official Journal of the Division of Health Psychology, American Psychological Association, 32(3), 293-301. https://doi.org/10.1037/a0028586

Dahl, C. J., Lutz, A., \& Davidson, R. J. (2015). Reconstructing and deconstructing the self: Cognitive mechanisms in meditation practice. Trends in Cognitive Sciences. https://doi.org/10.1016/j.tics.2015.07.001

Dahl, C. J., Wilson-Mendenhall, C. D., \& Davidson, R. J. (2020). The plasticity of well-being: A training-based framework for the cultivation of human flourishing. Proceedings of the National Academy of Sciences. https://doi.org/10.1073/pnas.2014859117

Davidson, R. J., \& McEwen, B. S. (2012). Social influences on neuroplasticity: Stress and interventions to promote well-being. Nature Neuroscience, 15(5), 689-695.

Dimidjian, S., \& Hollon, S. D. (2010). How would we know if psychotherapy were harmful? American Psychologist, 65(1), 21. 
Dworkin, R. H., Turk, D. C., Wyrwich, K. W., Beaton, D., Cleeland, C. S., Farrar, J. T., Haythornthwaite, J. A., Jensen, M. P., Kerns, R. D., Ader, D. N., Brandenburg, N., Burke, L. B., Cella, D., Chandler, J., Cowan, P., Dimitrova, R., Dionne, R., Hertz, S., Jadad, A. R., ... Zavisic, S. (2008). Interpreting the Clinical Importance of Treatment Outcomes in Chronic Pain Clinical Trials: IMMPACT Recommendations. The Journal of Pain, 9(2), 105-121. https://doi.org/10.1016/j.jpain.2007.09.005

Ehring, T., \& Ehlers, A. (2014). Does rumination mediate the relationship between emotion regulation ability and posttraumatic stress disorder? European Journal of Psychotraumatology, 5(1), 23547.

Ehring, T., Zetsche, U., Weidacker, K., Wahl, K., Schönfeld, S., \& Ehlers, A. (2011). The Perseverative Thinking Questionnaire (PTQ): Validation of a content-independent measure of repetitive negative thinking. Journal of Behavior Therapy and Experimental Psychiatry, 42(2), 225-232. https://doi.org/10.1016/j.jbtep.2010.12.003

Enders, C. K. (2001). The performance of the full information maximum likelihood estimator in multiple regression models with missing data. Educational and Psychological Measurement, 61(5), 713-740.

Ettman, C. K., Abdalla, S. M., Cohen, G. H., Sampson, L., Vivier, P. M., \& Galea, S. (2020). Prevalence of Depression Symptoms in US Adults Before and During the COVID-19 Pandemic. JAMA Network Open, 3(9), e2019686. https://doi.org/10.1001/jamanetworkopen.2020.19686

Feingold, A. (2009). Effect Sizes for Growth-Modeling Analysis for Controlled Clinical Trials in the Same Metric as for Classical Analysis. Psychological Methods, 14(1), 43-53. https://doi.org/10.1037/a0014699 
Folkman, S., \& Lazarus, R. S. (1988). Coping as a mediator of emotion. Journal of Personality and Social Psychology, 54(3), 466.

Forman, E. M., Herbert, J. D., Juarascio, A. S., Yeomans, P. D., Zebell, J. A., Goetter, E. M., \& Moitra, E. (2012). The Drexel defusion scale: A new measure of experiential distancing. Journal of Contextual Behavioral Science, 1(1-2), 55-65.

https://doi.org/10.1016/j.jcbs.2012.09.001

Galante, J., Dufour, G., Vainre, M., Wagner, A. P., Stochl, J., Benton, A., Lathia, N., Howarth, E., \& Jones, P. B. (2018). A mindfulness-based intervention to increase resilience to stress in university students (the Mindful Student Study): A pragmatic randomised controlled trial. The Lancet Public Health, 3(2), e72-e81. https://doi.org/10.1016/S24682667(17)30231-1

García, E., \& Weiss, E. (2019). Low relative pay and high incidence of moonlighting play a role in the teacher shortage, particularly in high-poverty schools. Economic Policy Institute, 17.

Garcia, Emma; Weiss, Elaine. (n.d.). Policy solutions to deal with the nation's teacher shortage-A crisis made worse by COVID-19. Economic Policy Institute. Retrieved February 11, 2021, from https:/www.epi.org/blog/policy-solutions-to-deal-with-thenations-teacher-shortage-a-crisis-made-worse-by-covid-19/

Goldberg, S. B., Bolt, D. M., \& Davidson, R. J. (2021). Data Missing Not at Random in Mobile Health Research: Assessment of the Problem and a Case for Sensitivity Analyses. Journal of Medical Internet Research, 23(6), e26749. https://doi.org/10.2196/26749

Goldberg, S. B., Riordan, K. M., Sun, S., \& Davidson, R. J. (2021). The Empirical Status of Mindfulness-Based Interventions: A Systematic Review of 44 Meta-Analyses of 
Randomized Controlled Trials. Perspectives on Psychological Science, 1745691620968771. https://doi.org/10.1177/1745691620968771

Goldberg, S. B., Tucker, R. P., Greene, P. A., Davidson, R. J., Wampold, B. E., Kearney, D. J., \& Simpson, T. L. (2018). Mindfulness-based interventions for psychiatric disorders: A systematic review and meta-analysis. Clinical Psychology Review, 59, 52-60. https://doi.org/10.1016/j.cpr.2017.10.011

Goldberg, S. B., Wielgosz, J., Dahl, C., Schuyler, B., MacCoon, D. S., Rosenkranz, M., Lutz, A., Sebranek, C. A., \& Davidson, R. J. (2015). Does the Five Facet Mindfulness Questionnaire Measure What We Think It Does? Construct Validity Evidence From an Active Controlled Randomized Clinical Trial. Psychological Assessment, No Pagination Specified. https://doi.org/10.1037/pas0000233

Goldhaber, D., Lavery, L., \& Theobald, R. (2015). Uneven Playing Field? Assessing the Teacher Quality Gap Between Advantaged and Disadvantaged Students. Educational Researcher, 44(5), 293-307. https://doi.org/10.3102/0013189X15592622

Goyal, M., Singh, S., Sibinga, E. M., Gould, N. F., Rowland-Seymour, A., Sharma, R., Berger, Z., Sleicher, D., Maron, D. D., Shihab, H. M., \& others. (2014). Meditation programs for psychological stress and well-being: A systematic review and meta-analysis. JAMA Internal Medicine, 174(3), 357-368.

Hancock, C. B., \& Scherff, L. (2010). Who Will Stay and Who Will Leave? Predicting Secondary English Teacher Attrition Risk. Journal of Teacher Education, 61(4), 328338. https://doi.org/10.1177/0022487110372214

Hanushek, E. A. (2011). The economic value of higher teacher quality. Economics of Education Review, 30(3), 466-479. Scopus. https://doi.org/10.1016/j.econedurev.2010.12.006 
Hartig, F. (2020). DHARMa: Residual Diagnostics for Hierarchical (Multi-Level / Mixed) Regression Models. $R$ (package version 0.3.3.0.) [Computer software]. https://CRAN.Rproject.org/package $=$ DHARMa

Hays, R. D., Hayashi, T., \& Stewart, A. L. (1989). A five-item measure of socially desirable response set. Educational and Psychological Measurement, 49(3), 629-636.

Hirshberg, M. J., Flook, L., Enright, R. D., \& Davidson, R. J. (2020). Integrating mindfulness and connection practices into preservice teacher education improves classroom practices. Learning and Instruction, 66, 101298. https://doi.org/10.1016/j.learninstruc.2019.101298

Hirshberg, M. J., Goldberg, S. B., Rosenkranz, M., \& Davidson, R. J. (2020). Prevalence of harm in mindfulness-based stress reduction. Psychological Medicine, 1-9. https://doi.org/10.1017/S0033291720002834

Holmes, E. A., O’Connor, R. C., Perry, V. H., Tracey, I., Wessely, S., Arseneault, L., Ballard, C., Christensen, H., Cohen Silver, R., Everall, I., Ford, T., John, A., Kabir, T., King, K., Madan, I., Michie, S., Przybylski, A. K., Shafran, R., Sweeney, A., ... Bullmore, E. (2020). Multidisciplinary research priorities for the COVID-19 pandemic: A call for action for mental health science. The Lancet Psychiatry, 7(6), 547-560. https://doi.org/10.1016/S2215-0366(20)30168-1

Iddrisu, A.-K., \& Gumedze, F. (2019). An application of a pattern-mixture model with multiple imputation for the analysis of longitudinal trials with protocol deviations. BMC Medical Research Methodology, 19(1), 10. https://doi.org/10.1186/s12874-018-0639-y

Jacobson, N. S., \& Truax, P. (1991). Clinical significance: A statistical approach to defining meaningful change in psychotherapy research. Journal of Consulting and Clinical Psychology, 59(1), 12. 
Jennings, P. A., Brown, J. L., Frank, J. L., Doyle, S., Oh, Y., Davis, R., Rasheed, D., DeWeese, A., DeMauro, A. A., Cham, H., \& Greenberg, M. T. (2017). Impacts of the CARE for Teachers Program on Teachers' Social and Emotional Competence and Classroom Interactions. Journal of Educational Psychology. http://dx.doi.org.ezproxy.library.wisc.edu/10.1037/edu0000187

Jennings, P. A., \& Greenberg, M. T. (2009). The prosocial classroom: Teacher social and emotional competence in relation to student and classroom outcomes. Review of Educational Research, 79(1), 491-525.

Kabat-Zinn, J. (1982). An outpatient program in behavioral medicine for chronic pain patients based on the practice of mindfulness meditation: Theoretical considerations and preliminary results. General Hospital Psychiatry, 4(1), 33-47.

Kabat-Zinn, J. (2013). Full catastrophe living, revised edition: How to cope with stress, pain and illness using mindfulness meditation. Hachette UK.

Kalin, N. H. (2020). The critical relationship between anxiety and depression. American Journal of Psychiatry, 1, 365-367 https://doi.org/10.1176/appi.ajp.2020.20030305

Klingbeil, D. A., \& Renshaw, T. L. (2018). Mindfulness-based interventions for teachers: A meta-analysis of the emerging evidence base. School Psychology Quarterly, 33(4), 501511. https://doi.org/10.1037/spq0000291

Klusmann, U., Kunter, M., Trautwein, U., Lüdtke, O., \& Baumert, J. (2008). Teachers’ occupational well-being and quality of instruction: The important role of self-regulatory patterns. Journal of Educational Psychology, 100(3), 702. 
Klusmann, U., Richter, D., \& Lüdtke, O. (2016). Teachers’ emotional exhaustion is negatively related to students' achievement: Evidence from a large-scale assessment study. Journal of Educational Psychology, 108(8), 1193-1203. https://doi.org/10.1037/edu0000125

Knudsen, E. I., Heckman, J. J., Cameron, J. L., \& Shonkoff, J. P. (2006). Economic, neurobiological, and behavioral perspectives on building America’s future workforce. Proceedings of the National Academy of Sciences, 103(27), 10155-10162.

Kyriacou, C. (2001). Teacher stress: Directions for future research. Educational Review, 53(1), $27-35$.

Lazarus, R. S., \& Folkman, S. (1984). Coping and adaptation. The Handbook of Behavioral Medicine, 282325.

Leurent, B., Gomes, M., Faria, R., Morris, S., Grieve, R., \& Carpenter, J. R. (2018). Sensitivity Analysis for Not-at-Random Missing Data in Trial-Based Cost-Effectiveness Analysis: A Tutorial. Pharmacoeconomics, 36(8), 889-901. https://doi.org/10.1007/s40273-0180650-5

Linardon, J. (2019). Can Acceptance, Mindfulness, and Self-Compassion Be Learned by Smartphone Apps? A Systematic and Meta-Analytic Review of Randomized Controlled Trials. Behavior Therapy, S0005789419301236.

https://doi.org/10.1016/j.beth.2019.10.002

Linardon, J., \& Fuller-Tyszkiewicz, M. (2020). Attrition and adherence in smartphone-delivered interventions for mental health problems: A systematic and meta-analytic review. Journal of Consulting and Clinical Psychology, 88(1), 1-13. https://doi.org/10.1037/ccp0000459 
Lindsay, E. K., \& Creswell, J. D. (2017). Mechanisms of mindfulness training: Monitor and Acceptance Theory (MAT). Clinical Psychology Review, 51(Supplement C), 48-59. https://doi.org/10.1016/j.cpr.2016.10.011

Lindsay, E. K., Young, S., Brown, K. W., Smyth, J. M., \& Creswell, J. D. (2019). Mindfulness training reduces loneliness and increases social contact in a randomized controlled trial. Proceedings of the National Academy of Sciences, 201813588. https://doi.org/10.1073/pnas.1813588116

Liu, X. (2016). Chapter 1-Introduction. In X. Liu (Ed.), Methods and Applications of Longitudinal Data Analysis (pp. 1-18). Academic Press. https://doi.org/10.1016/B978-0$12-801342-7.00001-0$

Markowitz, A. J., Bassok, D., Smith, A., \& Kiscaden, S. (2020). ChildCareTeachers'Experiences with COVID-19: Findings from the Study of Early Education in Louisiana. EdPolicyWorks at the University of Virginia, UCLA Graduate School of Education and Information Studies, 17.

Mitani, H. (2018). Principals' working conditions, job stress, and turnover behaviors under NCLB accountability pressure. Educational Administration Quarterly, 54(5), 822-862.

Naragon-Gainey, K., \& DeMarree, K. G. (2017). Structure and validity of measures of decentering and defusion. Psychological Assessment, 29(7), 935-954. https://doi.org/10.1037/pas0000405

Nolen-Hoeksema, S., Wisco, B. E., \& Lyubomirsky, S. (2008). Rethinking Rumination. Perspectives on Psychological Science: A Journal of the Association for Psychological Science, 3(5), 400-424. https://doi.org/10.1111/j.1745-6924.2008.00088.x 
Orben, A., Tomova, L., \& Blakemore, S.-J. (2020). The effects of social deprivation on adolescent development and mental health. The Lancet Child \& Adolescent Health, 4(8), 634-640. https://doi.org/10.1016/S2352-4642(20)30186-3

Ozamiz-Etxebarria, N., Berasategi Santxo, N., Idoiaga Mondragon, N., \& Dosil Santamaría, M. (2021). The Psychological State of Teachers During the COVID-19 Crisis: The Challenge of Returning to Face-to-Face Teaching. Frontiers in Psychology, 11. https://doi.org/10.3389/fpsyg.2020.620718

Park, Y.-T. (2016). Emerging New Era of Mobile Health Technologies. Healthcare Informatics Research, 22(4), 253-254. https://doi.org/10.4258/hir.2016.22.4.253

Pilkonis, P. A., Choi, S. W., Reise, S. P., Stover, A. M., Riley, W. T., Cella, D., \& PROMIS Cooperative Group. (2011). Item Banks for Measuring Emotional Distress From the Patient-Reported Outcomes Measurement Information System (PROMIS®): Depression, Anxiety, and Anger. Assessment, 18(3), 263-283. https://doi.org/10.1177/1073191111411667

Raes, F., Pommier, E., Neff, K. D., \& Van Gucht, D. (2011). Construction and factorial validation of a short form of the self-compassion scale. Clinical Psychology \& Psychotherapy, 18(3), 250-255.

Rivkin, S. G., Hanushek, E. A., \& Kain, J. F. (2005). Teachers, schools, and academic achievement. Econometrica, 417-458.

Roberti, J. W., Harrington, L. N., \& Storch, E. A. (2006). Further Psychometric Support for the 10-Item Version of the Perceived Stress Scale. Journal of College Counseling, 9(2), 135147. https://doi.org/10.1002/j.2161-1882.2006.tb00100.x 
Roeser, R. W., Schonert-Reichl, K. A., Jha, A., Cullen, M., Wallace, L., Wilensky, R., Oberle, E., Thomson, K., Taylor, C., \& Harrison, J. (2013). Mindfulness training and reductions in teacher stress and burnout: Results from two randomized, waitlist-control field trials. Journal of Educational Psychology, 105(3), 787-804. https://doi.org/10.1037/a0032093

Ronfeldt, M., Loeb, S., \& Wyckoff, J. (2013). How Teacher Turnover Harms Student Achievement. American Educational Research Journal, 50(1), 4-36. https://doi.org/10.3102/0002831212463813

Rubin, D. B. (2004). Multiple imputation for nonresponse in surveys (Vol. 81). John Wiley \& Sons.

Ryan, S. V., von der Embse, N. P., Pendergast, L. L., Saeki, E., Segool, N., \& Schwing, S. (2017). Leaving the teaching profession: The role of teacher stress and educational accountability policies on turnover intent. Teaching and Teacher Education, 66, 1-11. https://doi.org/10.1016/j.tate.2017.03.016

Schalet, B. D., Pilkonis, P. A., Yu, L., Dodds, N., Johnston, K. L., Yount, S., Riley, W., \& Cella, D. (2016). Clinical Validity of PROMIS ${ }^{\circledR}$ Depression, Anxiety, and Anger across Diverse Clinical Samples. Journal of Clinical Epidemiology, 73, 119-127. https://doi.org/10.1016/j.jclinepi.2015.08.036

Schonert-Reichl, K. A. (2019). Advancements in the Landscape of Social and Emotional Learning and Emerging Topics on the Horizon. Educational Psychologist, 54(3), 222232. https://doi.org/10.1080/00461520.2019.1633925

Schulenberg, S. E., Strack, K. M., \& Buchanan, E. M. (2011). The meaning in life questionnaire: Psychometric properties with individuals with serious mental illness in an inpatient 
setting. Journal of Clinical Psychology, 67(12), 1210-1219.

https://doi.org/10.1002/jclp.20841

Segal, Z. V., Dimidjian, S., Beck, A., Boggs, J. M., Vanderkruik, R., Metcalf, C. A., Gallop, R., Felder, J. N., \& Levy, J. (2020). Outcomes of Online Mindfulness-Based Cognitive Therapy for Patients With Residual Depressive Symptoms: A Randomized Clinical Trial. JAMA Psychiatry, 77(6), 563. https://doi.org/10.1001/jamapsychiatry.2019.4693

Sorensen, L. C., \& Ladd, H. F. (2020). The Hidden Costs of Teacher Turnover. AERA Open, 6(1), 2332858420905812. https://doi.org/10.1177/2332858420905812

Steger, M. F., Frazier, P., Oishi, S., \& Kaler, M. (2006). The meaning in life questionnaire: Assessing the presence of and search for meaning in life. Journal of Counseling Psychology, 53(1), 80.

Sunderland, M., Batterham, P., Calear, A., \& Carragher, N. (2018). Validity of the PROMIS depression and anxiety common metrics in an online sample of Australian adults. Quality of Life Research, 27(9), 2453-2458. https://doi.org/10.1007/s11136-018-1905-5

Team, R. C. (2014). R: A language and environment for statistical computing. $R$ Foundation for Statistical Computing, Vienna, Austria, 2012. ISBN 3-900051-07-0.

Thapa, A., Cohen, J., Guffey, S., \& Higgins-D’Alessandro, A. (2013). A Review of School Climate Research. Review of Educational Research, 83(3), 357-385. https://doi.org/10.3102/0034654313483907

Topp, C. W., Østergaard, S. D., Søndergaard, S., \& Bech, P. (2015). The WHO-5 Well-Being Index: A systematic review of the literature. Psychotherapy and Psychosomatics, 84(3), 167-176. https://doi.org/10.1159/000376585 
U.S. Department of Education. (2021). Monthly School Survey Dashboard. https://ies.ed.gov/schoolsurvey/

US Department of Education, Institute for Educational Science. (2018). Digest of Education Statistics, 2016. https://nces.ed.gov/programs/digest/d17/tables/dt17_209.10.asp?current=yes

Vago, D. R., \& Silbersweig, D. A. (2012). Self-awareness, self-regulation, and selftranscendence (S-ART): A framework for understanding the neurobiological mechanisms of mindfulness. Frontiers in Human Neuroscience, 6. http:/www.ncbi.nlm.nih.gov/pmc/articles/PMC3480633/

Wells, C. M., \& Klocko, B. A. (2018). Principal Well-Being and Resilience: Mindfulness as a Means to That End. NASSP Bulletin, 102(2), 161-173. https://doi.org/10.1177/0192636518777813

Zee, M., \& Koomen, H. M. Y. (2016). Teacher Self-Efficacy and Its Effects on Classroom Processes, Student Academic Adjustment, and Teacher Well-Being: A Synthesis of 40 Years of Research. Review of Educational Research, 86(4), 981-1015. https://doi.org/10.3102/0034654315626801 
Table 1

Baseline Demographic Characteristics by Group

\begin{tabular}{|c|c|c|}
\hline & $\begin{array}{l}\text { HMP Group } \\
(\mathrm{n}=344)\end{array}$ & $\begin{array}{l}\text { WLC Group } \\
(\mathrm{n}=318)\end{array}$ \\
\hline \multicolumn{3}{|l|}{ Gender } \\
\hline Female & $302(86.9 \%)$ & $281(88.4 \%)$ \\
\hline Male & $42(12.2 \%)$ & $37(11.6 \%)$ \\
\hline Non-binary & $1(0.3 \%)^{*}$ & $0(0.0 \%)$ \\
\hline \multicolumn{3}{|l|}{ Age (years) } \\
\hline$<20$ & $0(0.0 \%)$ & $1(0.2 \%)$ \\
\hline $20-30$ & $55(16.0 \%)$ & $46(14.5 \%)$ \\
\hline $30-40$ & $105(30.5 \%)$ & $90(28.3 \%)$ \\
\hline $40-50$ & $103(29.9 \%)$ & $93(29.3 \%)$ \\
\hline $50-60$ & $61(17.7 \%)$ & $79(24.8 \%)$ \\
\hline$>60$ & $20(5.8 \%)$ & $9(2.8 \%)$ \\
\hline \multicolumn{3}{|l|}{ Race / Ethnicity* } \\
\hline $\begin{array}{l}\text { American Indian / Alaskan } \\
\text { Native }\end{array}$ & $5(1.5 \%)$ & $4(1.3 \%)$ \\
\hline Asian / Pacific Islander & $9(2.6 \%)$ & $4(1.3 \%)$ \\
\hline Black / African American & $11(3.2 \%)$ & $15(4.7 \%)$ \\
\hline Hispanic/ Latino & $15(4.4 \%)$ & $17(5.3 \%)$ \\
\hline White / Caucasian & $315(91.6 \%)$ & $287(90.3 \%)$ \\
\hline \multicolumn{3}{|l|}{ Highest Education Level } \\
\hline$<7$ years formal education & $1(0.3 \%)$ & $2(0.6 \%)$ \\
\hline Graduated high school & $10(2.9 \%)$ & $6(1.9 \%)$ \\
\hline Some college & $24(7.0 \%)$ & $27(8.5 \%)$ \\
\hline Graduated college & $100(29.1 \%)$ & $103(32.4 \%)$ \\
\hline Advanced degree & $208(60.5 \%)$ & $178(56.0 \%)$ \\
\hline NA & $1(0.3 \%)$ & $2(0.6 \%)$ \\
\hline \multicolumn{3}{|l|}{ Household income (US Dollars) } \\
\hline$<\$ 20,000$ & $8(2.3 \%)$ & $9(2.8 \%)$ \\
\hline$\$ 20,000-\$ 40,000$ & $22(6.4 \%)$ & $19(6.0 \%)$ \\
\hline$\$ 40,000-\$ 70,000$ & $80(23.3 \%)$ & $82(25.8 \%)$ \\
\hline$\$ 70,000-\$ 100,000$ & $87(25.3 \%)$ & $74(23.3 \%)$ \\
\hline$\$ 100,000-\$ 200,000$ & $135(39.2 \%)$ & $121(38.5 \%)$ \\
\hline$>\$ 200,000$ & $9(2.6 \%)$ & $12(3.8 \%)$ \\
\hline \multicolumn{3}{|l|}{ Employment category } \\
\hline Classroom teacher & $144(41.9 \%)$ & $134(42.1 \%)$ \\
\hline Classroom support & $47(13.7 \%)$ & $44(13.8 \%)$ \\
\hline Special Education teacher & $29(8.4 \%)$ & $31(9.8 \%)$ \\
\hline School support & $38(11.1 \%)$ & $35(11.0 \%)$ \\
\hline $\begin{array}{l}\text { School administrator (e.g., } \\
\text { Principal) }\end{array}$ & $8(2.3 \%)$ & $4(1.3 \%)$ \\
\hline System staff & $20(5.8 \%)$ & $27(8.5 \%)$ \\
\hline Other / Unknown & $58(16.9 \%)$ & $43(13.5 \%)$ \\
\hline
\end{tabular}

Note: Data are n (\%). Gender does not sum to $100 \%$ because participants were able to select multiple categories. Race / Ethnicity does not sum to $100 \%$ because participants were able to select multiple categories. 


\section{Figure 1}

\section{Theory of Change}

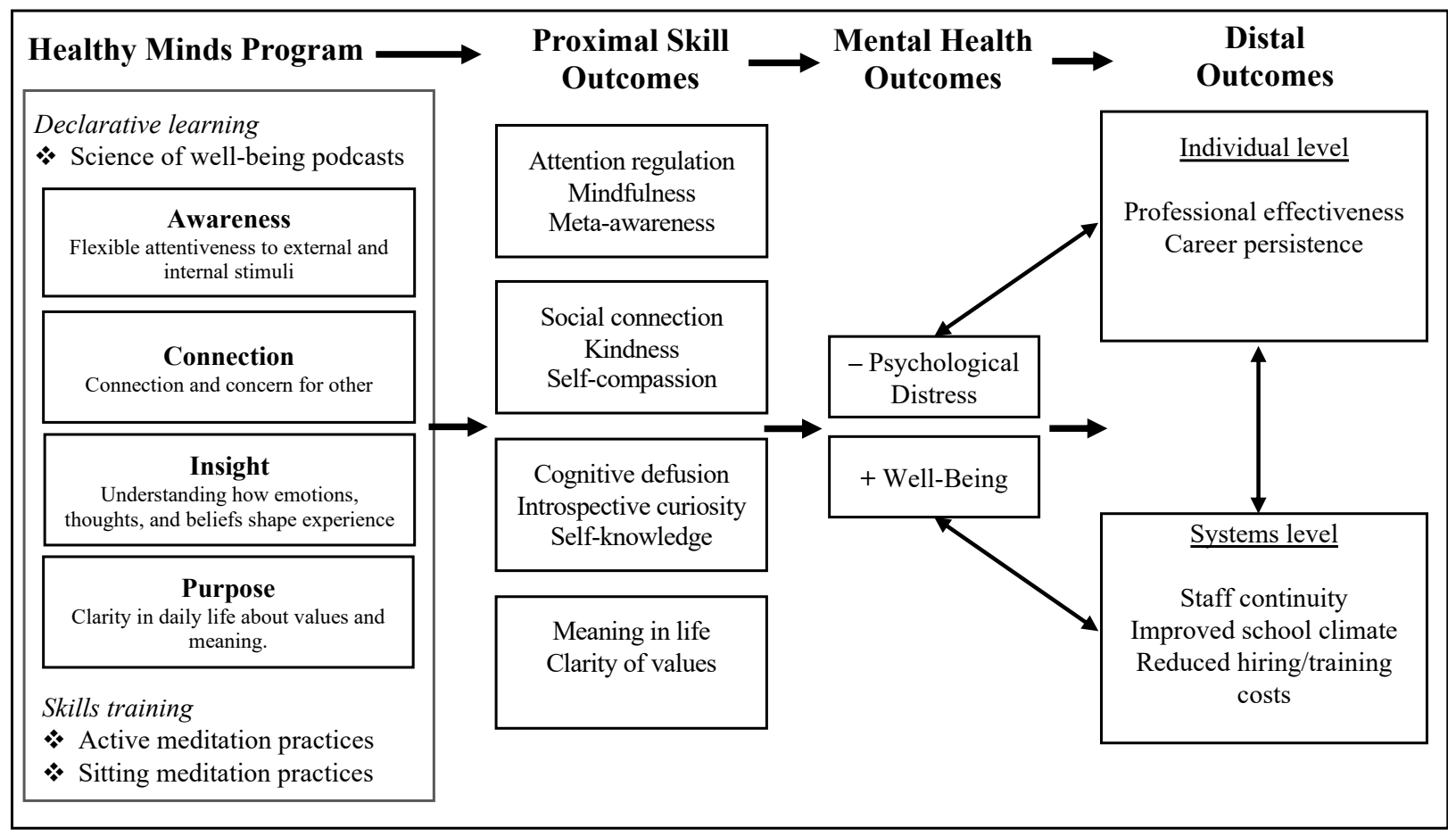

Note: Declarative learning is learning about well-being, well-being skills, and the role of training well-being skills in well-being. Skills training is experiential practice of well-being skills through traditional sitting forms of meditation and active practices. Active practices are a unique feature of the Healthy Minds Program in which mundane daily activities are utilized as opportunities to strengthen specific well-being skills. Proximal outcomes are not inclusive but instead represent constructs associated with each ACIP domain that were assessed in this study. Distal outcomes are likewise not inclusive but instead represent potential individual and system-level impacts of training proximal skills and improving mental health outcomes in school system employees. 


\section{Figure 2}

\section{CONSORT Diagram}

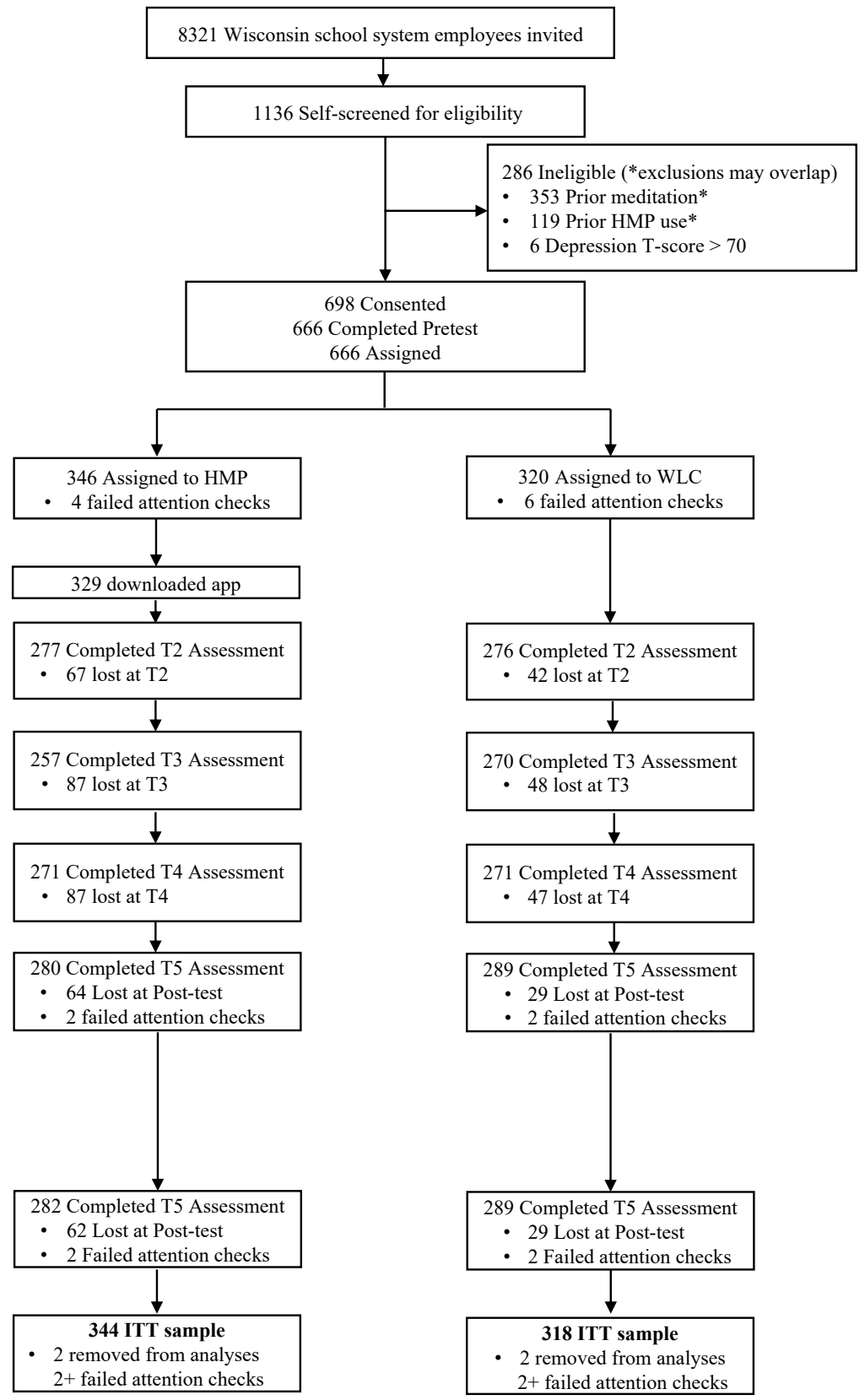

Note: HMP $=$ Healthy Minds Program. WLC $=$ Wait-list control. ITT $=$ intention-to-treat analysis. Lost $=$ participants providing no data at a timepoint. At T1, T5, and T6, data from participants failing two or more attention check questions were removed. Participants failing attention checks at two or more timepoints were removed from analyses, resulting in ITT sample. 


\section{Figure 3}

\section{Changes in Primary Outcome (Psychological Distress) Over Time by Group}

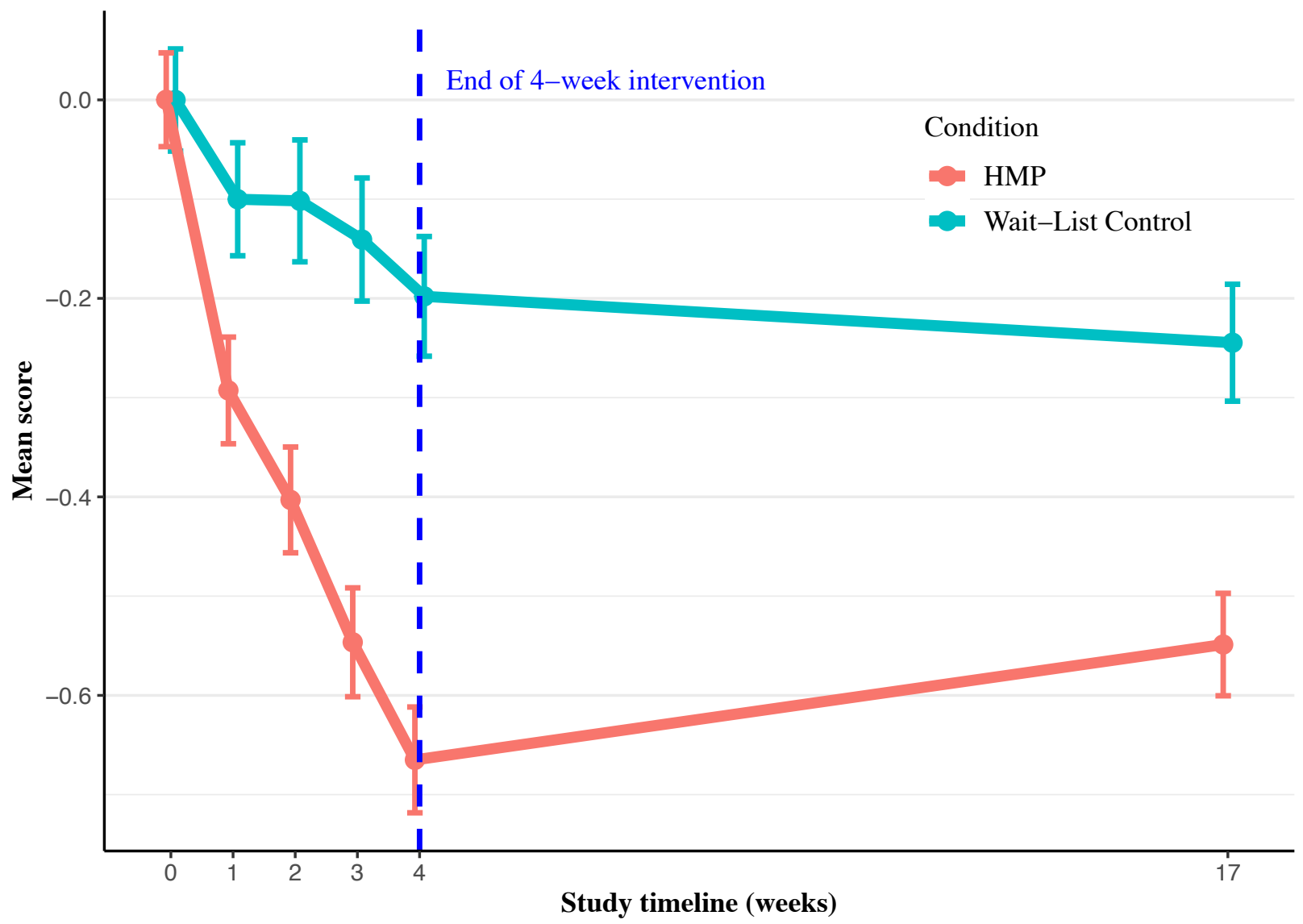

Note: Dotted blue line represents the end of the intervention period. 0 on the $\mathrm{x}$-axis is pre-test. Psychological distress is the z-scored aggregate of the NIH Perceived Stress Scale (Cohen et al., 1983), and the PROMIS anxiety and depression scales (Pilkonis et al., 2011). HMP = Healthy Minds Program (intervention arm). Error bars are standard error of the mean. Observed data plotted. 


\section{Figure 4}

\section{Changes in Secondary Outcomes Over Time by Group}
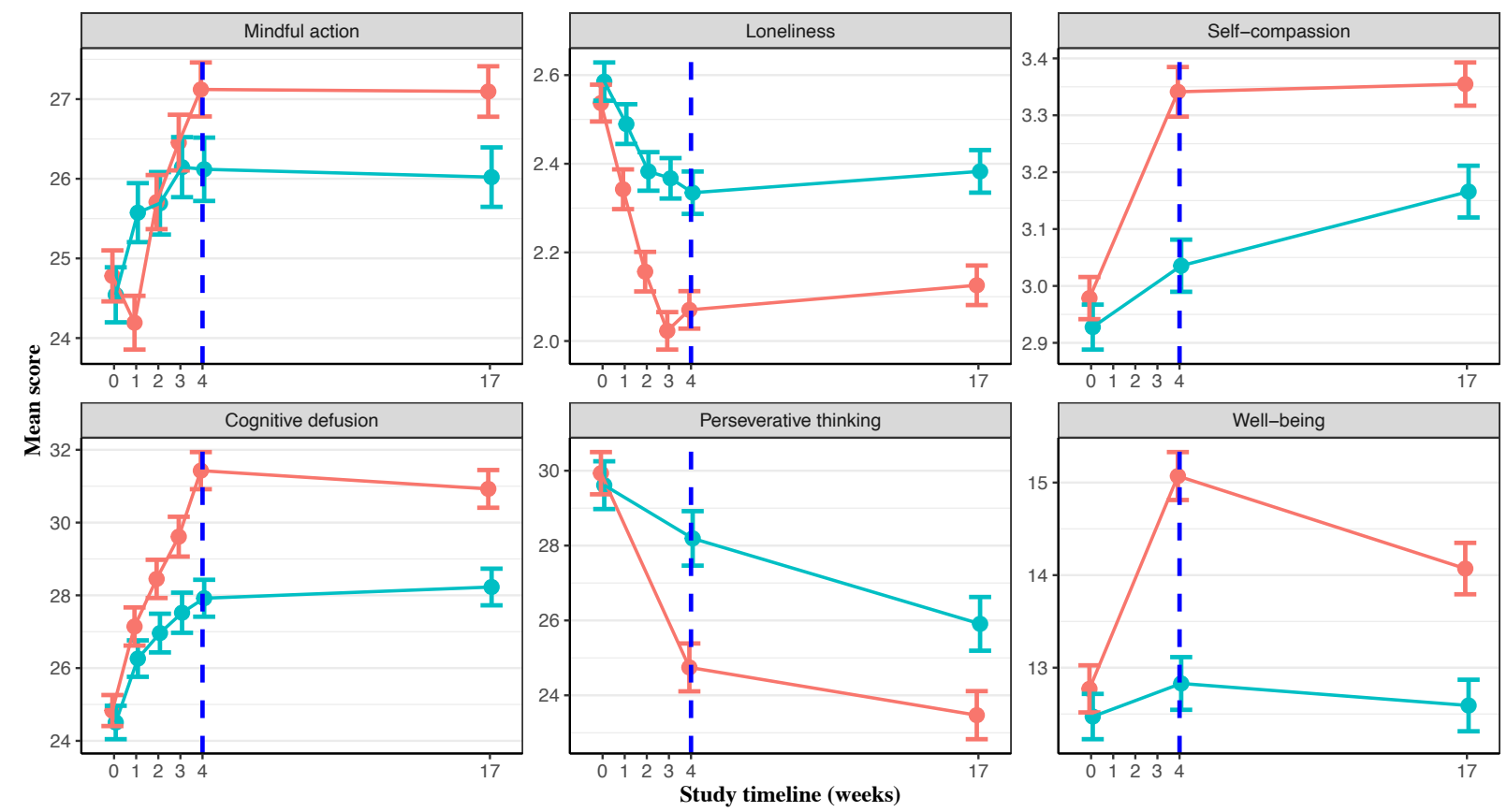

Condition - HMP $\sim$ Wait-list Contro

Note: Dotted blue line represents the end of the intervention period. X-axis ticks correspond to study weeks with 0 as pre-test. Mindful action was assessed with the Act with awareness subscale of the Five Facet Mindfulness Questionnaire (Baer et al., 2008). Loneliness was assessed with the NIH Toolbox Loneliness Questionnaire (Cyranowski et al., 2013). Selfcompassion was assessed with the Self-Compassion Short Form (Raes et al., 2011). Cognitive defusion was assessed with the Drexel Defusion Scale (Forman et al., 2012). Perseverative thinking was assessed with the Perseverative Thinking Questionnaire (Ehring et al., 2011). Wellbeing was assessed with the WHO-5 (Bech, 2004). HMP = Healthy Minds Program (intervention arm). Error bars are standard error of the mean. Observed data plotted. 


\section{Supplemental Materials}

\section{Table S1}

\section{Compensation Schedule}

\begin{tabular}{lc}
\hline Assessment & $\begin{array}{c}\text { Compensation (US } \\
\text { dollars) }\end{array}$ \\
\hline Baseline/Pre-Intervention (T1) & $\$ 0$ \\
After Week 1 (T2) & $\$ 10$ \\
After Week 2 (T3) & $\$ 10$ \\
After Week 3 (T4) & $\$ 10$ \\
Post-Intervention (T5) & $\$ 30$ \\
Bonus for Completing Above 5 & $\$ 40$ \\
Timepoints & \\
Follow-Up (T6) & $\$ 50$ \\
\hline
\end{tabular}

\section{Table S2}

\section{Attention Check Questions}

\begin{tabular}{ll}
\hline Item & \\
\hline 1 & Please select the leftmost response for this item (5 item Likert-like scale) \\
2 & I have been randomly selecting responses on this survey (yes/ no) \\
3 & I have provided my honest responses on this survey (5 item Likert-like scale) \\
\hline
\end{tabular}

Note: For item 1, failure is any response other than the leftmost response. For item 2, failure is a "yes" response. For item 3, failure is any response other than "Almost always" or "Always." 


\section{Table S3}

Results from Primary Piecewise Linear Mixed Effects Models, Models Including Social Desirability, and Models Including

\section{Participants Who Failed Attention Checks}

\begin{tabular}{|c|c|c|c|c|c|c|c|c|c|c|c|c|}
\hline \multirow[t]{3}{*}{ Outcome } & \multicolumn{3}{|c|}{ Psychological Distress } & \multicolumn{3}{|c|}{ Mindful Action } & \multicolumn{3}{|c|}{ Self-Compassion } & \multicolumn{3}{|c|}{ Loneliness } \\
\hline & $\mathrm{B}(\mathrm{SE})$ & $\mathrm{B}(\mathrm{SE})$ & $\mathrm{B}(\mathrm{SE})$ & $\mathrm{B}(\mathrm{SE})$ & $\mathrm{B}(\mathrm{SE})$ & $\mathrm{B}(\mathrm{SE})$ & $\mathrm{B}(\mathrm{SE})$ & $\mathrm{B}(\mathrm{SE})$ & $\mathrm{B}(\mathrm{SE})$ & $\mathrm{B}(\mathrm{SE})$ & $\mathrm{B}(\mathrm{SE})$ & $\mathrm{B}(\mathrm{SE})$ \\
\hline & Primary & $\begin{array}{c}\text { No } \\
\text { SDRS-5 }\end{array}$ & Assigned & Primary & $\begin{array}{c}\text { No } \\
\text { SDRS-5 }\end{array}$ & Assigned & Primary & $\begin{array}{c}\text { No } \\
\text { SDRS-5 }\end{array}$ & Assigned & Primary & $\begin{array}{c}\text { No } \\
\text { SDRS-5 }\end{array}$ & Assigned \\
\hline Intercept & $\begin{array}{c}0.08 \\
(0.17)\end{array}$ & $\begin{array}{c}0.07 \\
(0.17)\end{array}$ & $\begin{array}{c}0.06 \\
(0.17)\end{array}$ & $\begin{array}{c}24.32 * * * \\
(1.08)\end{array}$ & $\begin{array}{c}24.38 * * * \\
(1.08)\end{array}$ & $\begin{array}{c}23.69 * * * \\
(1.28)\end{array}$ & $\begin{array}{c}2.64 * * * \\
(0.13)\end{array}$ & $\begin{array}{c}2.62 * * * \\
(0.13)\end{array}$ & $\begin{array}{c}2.29 * * * \\
(0.16)\end{array}$ & $\begin{array}{c}2.31 * * * \\
(0.20)\end{array}$ & $\begin{array}{c}2.30 * * * \\
(0.13)\end{array}$ & $\begin{array}{c}2.61 * * * \\
(0.16)\end{array}$ \\
\hline T1-T5 & $\begin{array}{c}-0.04 * * * \\
(0.01)\end{array}$ & $\begin{array}{c}-0.04 * * * \\
(0.01)\end{array}$ & $\begin{array}{c}-0.04 * * * \\
(0.01)\end{array}$ & $\begin{array}{c}0.36 * * * \\
(0.07)\end{array}$ & $\begin{array}{c}0.36 * * * * \\
(0.07)\end{array}$ & $\begin{array}{c}0.07 \\
(0.15)\end{array}$ & $\begin{array}{c}0.02 * \\
(0.008)\end{array}$ & $\begin{array}{c}0.02 * \\
(0.008)\end{array}$ & $\begin{array}{c}-0.05 * * \\
(0.02)\end{array}$ & $\begin{array}{c}-0.06 * * * \\
(0.009)\end{array}$ & $\begin{array}{c}-0.06 * * * \\
(0.01)\end{array}$ & $\begin{array}{l}0.005 \\
(0.02)\end{array}$ \\
\hline Group & $\begin{array}{c}-0.50 * * * \\
(0.08)\end{array}$ & $\begin{array}{c}-0.50 * * * \\
(0.08)\end{array}$ & $\begin{array}{c}-0.50 * * * \\
(0.08\end{array}$ & $\begin{array}{c}0.68 \\
(0.48)\end{array}$ & $\begin{array}{c}0.72 \\
(0.48)\end{array}$ & $\begin{array}{c}0.70 \\
(0.48)\end{array}$ & $\begin{array}{c}0.33 * * * \\
(0.06)\end{array}$ & $\begin{array}{c}0.34 * * * \\
(0.06)\end{array}$ & $\begin{array}{c}0.34 * * * \\
(0.06)\end{array}$ & $\begin{array}{c}-0.30 * * * \\
(0.06)\end{array}$ & $\begin{array}{c}-0.30 * * * \\
(0.06)\end{array}$ & $\begin{array}{c}-0.30 * * * \\
(0.06)\end{array}$ \\
\hline T5- 6 & $\begin{array}{l}-0.004 \\
(0.002)\end{array}$ & $\begin{array}{l}-0.005 \\
(0.002)\end{array}$ & $\begin{array}{l}-0.005 \\
(0.002)\end{array}$ & $\begin{array}{l}-0.03 \\
(0.02)\end{array}$ & $\begin{array}{l}-0.03 \\
(0.02)\end{array}$ & $\begin{array}{l}-0.05 \\
(0.04)\end{array}$ & $\begin{array}{c}0.01 * * * \\
(0.002)\end{array}$ & $\begin{array}{c}0.01 * * * \\
(0.002)\end{array}$ & $\begin{array}{c}0.02 * * * \\
(0.005)\end{array}$ & $\begin{array}{c}0.006 * * \\
(0.002)\end{array}$ & $\begin{array}{l}0.006^{*} \\
(0.002)\end{array}$ & $\begin{array}{c}0 . .001 \\
(0.005)\end{array}$ \\
\hline Gender & $\begin{array}{c}0.29 * * \\
(0.10)\end{array}$ & $\begin{array}{c}0.27 * * \\
(0.10)\end{array}$ & $\begin{array}{c}0.27 * * \\
(0.10)\end{array}$ & $\begin{array}{l}-1.16 \\
(0.66)\end{array}$ & $\begin{array}{l}-1.11 \\
(0.67)\end{array}$ & $\begin{array}{l}-1.09 \\
(0.67)\end{array}$ & $\begin{array}{c}-0.15 \\
(0.08)\end{array}$ & $\begin{array}{l}-0.13 \\
(0.08)\end{array}$ & $\begin{array}{c}-0.13 \\
(0.08)\end{array}$ & $\begin{array}{c}0.16 \\
(0.08)\end{array}$ & $\begin{array}{c}0.15 \\
(0.08)\end{array}$ & $\begin{array}{c}0.15 \\
(0.08)\end{array}$ \\
\hline Race & $\begin{array}{c}0.17 \\
(0.11)\end{array}$ & $\begin{array}{c}0.15 \\
(0.11)\end{array}$ & $\begin{array}{c}0.15 \\
(0.11)\end{array}$ & $\begin{array}{c}1.14 \\
(0.71)\end{array}$ & $\begin{array}{c}0.98 \\
(0.70)\end{array}$ & $\begin{array}{c}1.03 \\
(0.70)\end{array}$ & $\begin{array}{c}0.01 \\
(0.09)\end{array}$ & $\begin{array}{c}0.01 \\
(0.09)\end{array}$ & $\begin{array}{c}0.01 \\
(0.09)\end{array}$ & $\begin{array}{c}0.15 \\
(0.09)\end{array}$ & $\begin{array}{c}0.13 \\
(0.09)\end{array}$ & $\begin{array}{c}0.13 \\
(0.09)\end{array}$ \\
\hline Age & $\begin{array}{c}-0.01 * * * \\
(0.003)\end{array}$ & $\begin{array}{c}-0.01 * * * \\
(0.003)\end{array}$ & $\begin{array}{c}-0.01 * * * \\
(0.003)\end{array}$ & $\begin{array}{c}0.06 * * \\
(0.02)\end{array}$ & $\begin{array}{c}0.07 * * \\
(0.02)\end{array}$ & $\begin{array}{c}0.07 * * \\
(0.09)\end{array}$ & $\begin{array}{c}0.01 * * * \\
(0.002)\end{array}$ & $\begin{array}{c}0.01 * * * \\
(0.002)\end{array}$ & $\begin{array}{c}0.01 * * * \\
(0.002)\end{array}$ & $\begin{array}{l}-0.002 \\
(0.003)\end{array}$ & $\begin{array}{l}-0.003 \\
(0.002)\end{array}$ & $\begin{array}{c}-0.03 \\
(0.003)\end{array}$ \\
\hline SDRS5 & $\begin{array}{c}-0.12 * * \\
(0.04)\end{array}$ & & & $\begin{array}{l}0.66^{*} \\
(0.26)\end{array}$ & & & $\begin{array}{c}0.12 * * * \\
(0.03)\end{array}$ & & & $\begin{array}{c}-0.09 * * \\
(0.03)\end{array}$ & & \\
\hline Group x T1-T5 & $\begin{array}{c}-0.12 * * * \\
(0.01)\end{array}$ & $\begin{array}{c}-0.12 * * * \\
(0.01)\end{array}$ & $\begin{array}{c}-0.12 * * * \\
(0.01)\end{array}$ & $\begin{array}{c}0.31 * * * \\
(0.09)\end{array}$ & $\begin{array}{c}0.31 * * \\
(0.09)\end{array}$ & $\begin{array}{c}0.30 * * \\
(0.09)\end{array}$ & $\begin{array}{c}0.07 * * * \\
(0.01)\end{array}$ & $\begin{array}{c}0.07 * * * \\
(0.01)\end{array}$ & $\begin{array}{c}0.07 * * * \\
(0.01)\end{array}$ & $\begin{array}{c}-0.07 * * * \\
(0.01)\end{array}$ & $\begin{array}{c}-0.07 * * * \\
(0.01)\end{array}$ & $\begin{array}{c}-0.06 * * * \\
(0.01)\end{array}$ \\
\hline Group x T1-T6 & $\begin{array}{c}-0.29 * * * \\
(0.08)\end{array}$ & $\begin{array}{c}-0.29 * * * \\
(0.08)\end{array}$ & $\begin{array}{c}-0.21 * * * \\
(0.05)\end{array}$ & $\begin{array}{c}0.83 \\
(0.46)\end{array}$ & $\begin{array}{c}1.08 * \\
(0.50)\end{array}$ & $\begin{array}{c}1.03 * \\
(0.50) \\
\end{array}$ & $\begin{array}{c}0.18 * * \\
(0.06)\end{array}$ & $\begin{array}{c}0.19 * * \\
(0.06)\end{array}$ & $\begin{array}{c}0.19 * * \\
(0.06)\end{array}$ & $\begin{array}{c}-0.25 * * * \\
(0.06)\end{array}$ & $\begin{array}{c}-0.24 * * * \\
(0.06)\end{array}$ & $\begin{array}{c}-0.24 * * * \\
(0.06)\end{array}$ \\
\hline
\end{tabular}


Table S3 Continued

\begin{tabular}{|c|c|c|c|c|c|c|c|c|c|c|c|c|}
\hline \multirow[t]{3}{*}{ Outcome } & \multicolumn{3}{|c|}{ Cognitive Defusion } & \multicolumn{3}{|c|}{ Perseverative Thinking } & \multicolumn{3}{|c|}{ Well-Being } & \multicolumn{3}{|c|}{ Meaning in Life } \\
\hline & $\mathrm{B}(\mathrm{SE})$ & $\mathrm{B}(\mathrm{SE})$ & $\mathrm{B}(\mathrm{SE})$ & $\mathrm{B}(\mathrm{SE})$ & $\mathrm{B}(\mathrm{SE})$ & $\mathrm{B}(\mathrm{SE})$ & $\mathrm{B}(\mathrm{SE})$ & $\mathrm{B}(\mathrm{SE})$ & $\mathrm{B}(\mathrm{SE})$ & $\mathrm{B}(\mathrm{SE})$ & $\mathrm{B}(\mathrm{SE})$ & $\mathrm{B}(\mathrm{SE})$ \\
\hline & Primary & $\begin{array}{c}\text { No } \\
\text { SDRS-5 }\end{array}$ & Assigned & Primary & $\begin{array}{c}\text { No } \\
\text { SDRS-5 }\end{array}$ & Assigned & Primary & $\begin{array}{c}\text { No } \\
\text { SDRS-5 }\end{array}$ & Assigned & Primary & $\begin{array}{c}\text { No } \\
\text { SDRS-5 }\end{array}$ & Assigned \\
\hline Intercept & $\begin{array}{c}26.86^{* * *} \\
(1.50)\end{array}$ & $\begin{array}{c}26.69 * * * \\
(1.50)\end{array}$ & $\begin{array}{c}25.16^{* * *} \\
(1.80)\end{array}$ & $\begin{array}{c}34.23 * * * \\
(2.05)\end{array}$ & $\begin{array}{c}34.31 * * * \\
(3.09)\end{array}$ & $\begin{array}{c}37.91 * * * \\
(2.44)\end{array}$ & $\begin{array}{c}12.24 * * * \\
(0.82)\end{array}$ & $\begin{array}{c}12.47 * * * \\
(0.83)\end{array}$ & $\begin{array}{c}10.30 * * * \\
(0.99)\end{array}$ & $\begin{array}{c}25.52 * * * \\
(0.99)\end{array}$ & $\begin{array}{c}25.53 * * * \\
(0.99)\end{array}$ & $\begin{array}{c}25.51 * * * \\
(1.00)\end{array}$ \\
\hline T1-T5 & $\begin{array}{c}0.79 * * * \\
(0.10)\end{array}$ & $\begin{array}{c}0.79 * * * \\
(0.10)\end{array}$ & $\begin{array}{c}-0.06 \\
(0.23)\end{array}$ & $\begin{array}{c}-0.29 * \\
(0.12)\end{array}$ & $\begin{array}{c}-0.29 * \\
(0.12)\end{array}$ & $\begin{array}{c}0.70 * * \\
(0.27)\end{array}$ & $\begin{array}{c}0.08 \\
(0.06)\end{array}$ & $\begin{array}{c}0.07 \\
(0.06)\end{array}$ & $\begin{array}{c}-0.37 * * \\
(0.14)\end{array}$ & $\begin{array}{c}0.05 \\
(0.06)\end{array}$ & $\begin{array}{c}0.05 \\
(0.06)\end{array}$ & $\begin{array}{c}0.04 \\
(0.06)\end{array}$ \\
\hline Group & $\begin{array}{c}3.39 * * * \\
(0.70)\end{array}$ & $\begin{array}{c}3.46^{* * *} \\
(0.69)\end{array}$ & $\begin{array}{c}3.52 * * * \\
(0.69)\end{array}$ & $\begin{array}{c}-3.47 * * * \\
(0.91)\end{array}$ & $\begin{array}{c}-3.60 * * * \\
(0.91)\end{array}$ & $\begin{array}{c}-3.61 * * * \\
(0.91)\end{array}$ & $\begin{array}{c}2.24 * * * \\
(0.38)\end{array}$ & $\begin{array}{c}2.19 * * * \\
(0.39)\end{array}$ & $\begin{array}{c}2.19 * * * \\
(0.39)\end{array}$ & $\begin{array}{c}1.96 * * * \\
(0.43)\end{array}$ & $\begin{array}{c}1.91 * * * \\
(0.43)\end{array}$ & $\begin{array}{c}1.99 * * * \\
(0.43)\end{array}$ \\
\hline T5- T6 & $\begin{array}{c}0.01 \\
(0.03)\end{array}$ & $\begin{array}{c}0.01 \\
(0.03)\end{array}$ & $\begin{array}{c}0.07 \\
(0.06)\end{array}$ & $\begin{array}{c}-0.18 * * * \\
(0.04)\end{array}$ & $\begin{array}{c}-0.18 * * * \\
(0.04)\end{array}$ & $\begin{array}{c}-0.28 * * * \\
(0.08)\end{array}$ & $\begin{array}{c}-0.02 \\
(0.02)\end{array}$ & $\begin{array}{l}-0.02 \\
(0.02)\end{array}$ & $\begin{array}{l}-0.02 \\
(0.04)\end{array}$ & $\begin{array}{c}0.02 \\
(0.01)\end{array}$ & $\begin{array}{c}0.02 \\
(0.02)\end{array}$ & $\begin{array}{c}0.02 \\
(0.01)\end{array}$ \\
\hline Gender & $\begin{array}{c}-3.12 * * * \\
(0.92)\end{array}$ & $\begin{array}{c}-2.87 * * \\
(0.92)\end{array}$ & $\begin{array}{c}-2.88 * * \\
(0.92)\end{array}$ & $\begin{array}{l}3.06^{*} \\
(1.26)\end{array}$ & $\begin{array}{l}2.84^{*} \\
(1.26)\end{array}$ & $\begin{array}{l}2.85^{*} \\
(1.26)\end{array}$ & $\begin{array}{l}-0.97 \\
(0.51)\end{array}$ & $\begin{array}{c}-1.06^{*} \\
(0.51)\end{array}$ & $\begin{array}{l}-0.96 \\
(0.51)\end{array}$ & $\begin{array}{c}0.40 \\
(0.61)\end{array}$ & $\begin{array}{c}0.30 \\
(0.61)\end{array}$ & $\begin{array}{c}0.38 \\
(0.61)\end{array}$ \\
\hline Race & $\begin{array}{l}-0.30 \\
(0.99)\end{array}$ & $\begin{array}{c}0.14 \\
(0.97)\end{array}$ & $\begin{array}{c}0.03 \\
(0.97)\end{array}$ & $\begin{array}{c}-0.64 \\
(1.36)\end{array}$ & $\begin{array}{l}-0.79 \\
(1.33)\end{array}$ & $\begin{array}{c}-0.74 \\
(1.33)\end{array}$ & $\begin{array}{c}0.05 \\
(0.53)\end{array}$ & $\begin{array}{l}-0.06 \\
(0.55)\end{array}$ & $\begin{array}{c}0.13 \\
(0.53)\end{array}$ & $\begin{array}{l}-0.10 \\
(0.65)\end{array}$ & $\begin{array}{l}-0.13 \\
(0.66)\end{array}$ & $\begin{array}{l}-0.18 \\
(0.65)\end{array}$ \\
\hline Age & $\begin{array}{c}0.08 * * \\
(0.03)\end{array}$ & $\begin{array}{c}0.09 * * \\
(0.03)\end{array}$ & $\begin{array}{c}0.09 * * \\
(0.03)\end{array}$ & $\begin{array}{c}-0.18 * * * \\
(0.04)\end{array}$ & $\begin{array}{c}-0.20 * * * \\
(0.04)\end{array}$ & $\begin{array}{c}-0.20 * * * \\
(0.04)\end{array}$ & $\begin{array}{c}0.03 \\
(0.02)\end{array}$ & $\begin{array}{c}0.02 \\
(0.02)\end{array}$ & $\begin{array}{c}0.03 \\
(0.02)\end{array}$ & $\begin{array}{l}0.003 \\
(0.02)\end{array}$ & $\begin{array}{l}-0.01 \\
(0.02)\end{array}$ & $\begin{array}{l}0.003 \\
(0.02)\end{array}$ \\
\hline SDRS5 & $\begin{array}{c}1.21 * * * \\
(0.36)\end{array}$ & & & $\begin{array}{c}-1.61 * * \\
(0.50)\end{array}$ & & & & $\begin{array}{l}0.49 * \\
(0.20)\end{array}$ & & & $\begin{array}{c}-0.48^{*} \\
(0.19)\end{array}$ & \\
\hline Group x T1-T5 & $\begin{array}{c}0.81 * * * \\
(0.15)\end{array}$ & $\begin{array}{c}0.80 * * * \\
(0.15)\end{array}$ & $\begin{array}{c}0.82 * * * \\
(0.15)\end{array}$ & $\begin{array}{c}-0.98 * * * \\
(0.17)\end{array}$ & $\begin{array}{c}-0.99 * * \\
(0.17)\end{array}$ & $\begin{array}{c}-1.00 * * \\
(0.17)\end{array}$ & $\begin{array}{c}0.48 * * * \\
(0.09)\end{array}$ & $\begin{array}{c}0.48 * * * \\
(0.09)\end{array}$ & $\begin{array}{c}0.47 * * * \\
(0.09)\end{array}$ & $\begin{array}{c}0.38 * * * \\
(0.08)\end{array}$ & $\begin{array}{c}0.38 * * * \\
(0.08)\end{array}$ & $\begin{array}{c}0.40 * * * \\
(0.08)\end{array}$ \\
\hline Group x T1-T6 & $\begin{array}{c}2.79 * * * \\
(0.73)\end{array}$ & $\begin{array}{c}2.83 * * * \\
(0.73)\end{array}$ & $\begin{array}{c}2.79 * * * \\
(0.72)\end{array}$ & $\begin{array}{l}-2.33^{*} \\
(1.25)\end{array}$ & $\begin{array}{l}-2.38 * \\
(1.22)\end{array}$ & $\begin{array}{c}-2.36^{*} \\
(0.93)\end{array}$ & $\begin{array}{c}1.57 * * * \\
(0.39)\end{array}$ & $\begin{array}{c}1.53 * * * \\
(0.39)\end{array}$ & $\begin{array}{c}1.57 * * * \\
(0.35)\end{array}$ & $\begin{array}{c}1.70 * * * \\
(0.06)\end{array}$ & $\begin{array}{c}1.64 * * * \\
(0.45)\end{array}$ & $\begin{array}{c}1.76 * * * \\
(0.45)\end{array}$ \\
\hline
\end{tabular}

Note: Primary = Intention-to-treat analyses with removal of participants failing attention checks $(N=662)$. SDRS-5 = Intention-to-treat

analyses controlling for Social Desirable Response Set 5 score $(\mathrm{N}=662)$. Assigned = Intention-to-treat analyses with all randomly

assigned participants $(N=666)$. Due to our coding of longitudinal data in R software, the Group x T1-T5 interaction coefficient (SE)

must be multiplied by four for consistency with the Group x T1-T6 coefficient. ${ }^{*} p<0.05,{ }^{* *} p<0.01,{ }^{* * *} p<0.001$ 


\section{Table S4}

\section{Missingness By Group at Each Timepoint}

\begin{tabular}{lcccccc}
\hline Group & \multicolumn{5}{c}{ \% Missing } \\
& $\mathrm{T} 1$ & $\mathrm{~T} 2$ & $\mathrm{~T} 3$ & $\mathrm{~T} 4$ & $\mathrm{~T} 5$ & T6 \\
\cline { 2 - 7 } Healthy Minds Program & $<1.00$ & 19.48 & 25.29 & 25.29 & 18.23 & 18.02 \\
Wait-List Control & 1.26 & 13.21 & 15.09 & 14.78 & 9.12 & 9.12 \\
\hline
\end{tabular}

Note: Missingness is based on presence of the primary outcomes, psychological distress. $\mathrm{T} 1=$

Pre-test before random assignment. T2 $=$ After week one of the intervention. T3 $=$ After week 2

of the intervention. $\mathrm{T} 4=$ After week three of the intervention. $\mathrm{T} 5=$ Post-test immediately

following the end of the intervention period. T6 = Follow-up test three-months after T5. 


\section{Table S5}

Outcome Score by Group at Each Assessment

\begin{tabular}{|c|c|c|c|c|c|c|c|c|c|c|c|c|}
\hline \multirow[t]{2}{*}{ Outcome } & \multicolumn{2}{|c|}{$\underline{\mathrm{T} 1}$} & \multicolumn{2}{|r|}{$\underline{\mathrm{T} 2}$} & \multicolumn{2}{|r|}{$\underline{\mathrm{T} 3}$} & \multicolumn{2}{|r|}{$\underline{\mathrm{T} 4}$} & \multicolumn{2}{|c|}{$\underline{\text { (Post-intervention) }}$} & \multicolumn{2}{|c|}{ (3-month follow-up) } \\
\hline & $\mathrm{n}$ & Mean (SD) & $\mathrm{n}$ & Mean (SD) & $\mathrm{n}$ & Mean (SD) & $\mathrm{n}$ & Mean (SD) & $\mathrm{n}$ & Mean (SD) & $\mathrm{n}$ & Mean (SD) \\
\hline \multicolumn{13}{|c|}{ Psychological distress } \\
\hline WLC & 315 & $0.00(0.91)$ & 276 & $-0.10(0.95)$ & 270 & $-0.10(1.01)$ & 271 & $-0.14(1.02)$ & 289 & $-0.20(1.03)$ & 289 & $-0.24(1.00)$ \\
\hline HMP & 342 & $0.00(0.88)$ & 277 & $-0.29(0.89)$ & 257 & $-0.40(0.85)$ & 257 & $-0.55(0.88)$ & 280 & $-0.67(0.89)$ & 282 & $-0.55(0.87)$ \\
\hline \multicolumn{13}{|c|}{ Mindful action } \\
\hline WLC & 315 & $24.56(6.12)$ & 276 & $25.57(6.15)$ & 270 & $25.69(6.44)$ & 271 & $26.15(6.21)$ & 289 & $26.12(6.76)$ & 290 & $26.02(6.36)$ \\
\hline HMP & 342 & $24.80(5.93)$ & 277 & $24.19(5.62)$ & 259 & $25.71(5.47)$ & 258 & $26.45(5.61)$ & 280 & $27.12(5.67)$ & 282 & $27.1(5.32)$ \\
\hline \multicolumn{13}{|c|}{ Self-compassion } \\
\hline WLC & 315 & $2.93(0.70)$ & & NA & & NA & & NA & 290 & $3.04(0.78)$ & 289 & $3.17(0.77)$ \\
\hline HMP & 342 & $2.98(0.69)$ & & NA & & NA & & NA & 280 & $3.34(0.73)$ & 280 & $3.35(0.64)$ \\
\hline \multicolumn{13}{|c|}{ Loneliness } \\
\hline WLC & 315 & $2.58(0.77)$ & 276 & $2.49(0.74)$ & 272 & $2.38(0.72)$ & 271 & $2.37(0.75)$ & 289 & $2.33(0.81)$ & 291 & $2.38(0.82)$ \\
\hline HMP & 342 & $2.53(0.77)$ & 278 & $2.34(0.75)$ & 260 & $2.16(0.72)$ & 259 & $2.02(0.68)$ & 279 & $2.07(0.71)$ & 283 & $2.13(0.75)$ \\
\hline \multicolumn{13}{|c|}{ Cognitive defusion } \\
\hline WLC & 315 & $24.45(8.23)$ & 275 & $26.26(8.31)$ & 270 & $26.96(8.73)$ & 270 & $27.52(9.07)$ & 289 & $27.92(8.63)$ & 289 & $28.23(8.57)$ \\
\hline HMP & 342 & $24.83(7.89)$ & 276 & $27.14(8.72)$ & 257 & $28.45(8.42)$ & 255 & $29.61(8.73)$ & 280 & $31.43(8.54)$ & 281 & $30.93(8.69)$ \\
\hline \multicolumn{13}{|c|}{ Perseverative thinking } \\
\hline WLC & 315 & $29.62(11.29)$ & & NA & & NA & & NA & 289 & $28.19(12.37)$ & 289 & $25.91(12.19)$ \\
\hline HMP & 342 & $29.89(10.43)$ & & NA & & NA & & NA & 280 & $24.75(10.71)$ & 280 & $23.47(10.74)$ \\
\hline \multicolumn{13}{|c|}{ Well-being } \\
\hline WLC & 315 & $12.47(4.33)$ & & NA & & NA & & NA & 289 & $12.83(4.84)$ & 289 & $12.59(4.74)$ \\
\hline HMP & 341 & $12.76(4.71)$ & & NA & & NA & & NA & 280 & $15.07(4.33)$ & 279 & $14.07(4.64)$ \\
\hline \multicolumn{13}{|c|}{ Meaning in life* } \\
\hline WLC & 315 & $25.81(5.46)$ & 276 & $26.02(5.38)$ & 270 & $25.85(5.68)$ & 271 & $26.13(5.83)$ & 289 & $26.02(46.07)$ & 290 & $26.29(5.87)$ \\
\hline HMP & 342 & $26.20(5.44)$ & 278 & $26.83(5.13)$ & 259 & $27.15(5.14)$ & 258 & $27.62(4.92)$ & 280 & $27.85(5.35)$ & 282 & $27.91(5.14)$ \\
\hline
\end{tabular}

Note: HMP is the Healthy Minds Program Foundations course group (i.e., intervention arm). WLC = Wait-list control group. NA $=$

Not assessed at that timepoint. Psychological distress is the aggregate of z-scored stress (Perceived Stress Scale), anxiety (PROMIS

Anxiety), and depression (PROMIS Depression) measures. *Outcome hypotheses not preregistered. 


\section{Table S6}

\section{Model Fit Statistics by Outcome}

\begin{tabular}{|c|c|c|c|c|c|c|}
\hline Model & Parameters & AIC & $\mathrm{BIC}$ & LogLik & $\begin{array}{c}\text { Chi-sq } \\
\text { (df) }\end{array}$ & $p$ \\
\hline \multicolumn{7}{|l|}{ Psychological distress } \\
\hline Linear & 9 & 6091 & 6146 & -3037 & & \\
\hline Log Linear & 9 & 5943 & 5998 & -2963 & $148(0)$ & 0 \\
\hline Piecewise & 11 & 5821 & 5888 & -2900 & $126(2)$ & $<0.0001$ \\
\hline Piecewise random slope & 13 & 5712 & 5791 & -2843 & $113(2)$ & $<0.0001$ \\
\hline \multicolumn{7}{|l|}{ Mindful action } \\
\hline Linear & 9 & 18284 & 18339 & -9133 & & \\
\hline Log Linear & 9 & 18212 & 18267 & -9097 & $71.8(0)$ & 0 \\
\hline Piecewise & 11 & 18153 & 18220 & -9065 & $63.5(2)$ & $<0.0001$ \\
\hline Piecewise random slope & 13 & 18070 & 18150 & -9022 & $86.5(2)$ & $<0.0001$ \\
\hline \multicolumn{7}{|l|}{ Self-compassion } \\
\hline Linear & 9 & 2802 & 2851 & -1392 & & \\
\hline Log Linear & 9 & 2745 & 2794 & -1363 & $57.1(0)$ & 0 \\
\hline Piecewise & 11 & 2713 & 2773 & -1345 & $35.9(2)$ & $<0.0001$ \\
\hline \multicolumn{7}{|l|}{ Loneliness } \\
\hline Linear & 9 & 5129 & 5184 & -2556 & & \\
\hline Log Linear & 9 & 4990 & 5045 & -2486 & $139(0)$ & 0 \\
\hline Piecewise & 11 & 4863 & 4930 & -2421 & $131(2)$ & $<0.0001$ \\
\hline Piecewise random slope & 13 & 4788 & 44868 & -2381 & $79(2)$ & $<0.0001$ \\
\hline \multicolumn{7}{|l|}{ Cognitive defusion } \\
\hline Linear & 9 & 21121 & 221176 & -10551 & & \\
\hline Log Linear & 9 & 20932 & 20987 & -10457 & $189(0)$ & 0 \\
\hline Piecewise & 11 & 20829 & 20896 & -10403 & $108(2)$ & $<0.0001$ \\
\hline Piecewise random slope & 13 & 20730 & 20809 & -10352 & $103(2)$ & $<0.0001$ \\
\hline \multicolumn{7}{|l|}{ Perseverative thinking } \\
\hline Linear & 9 & 12286 & 12335 & -6134 & & \\
\hline Log Linear & 9 & 12235 & 12284 & -6120 & $51.4(0)$ & 0 \\
\hline Piecewise & 11 & 12220 & 12280 & -6099 & $19(2)$ & $<0.0001$ \\
\hline \multicolumn{7}{|l|}{ Well-being } \\
\hline Linear & 9 & 9635 & 9684 & -4808 & & \\
\hline Log Linear & 9 & 9610 & 9659 & -4796 & $24.7(0)$ & 0 \\
\hline Piecewise & 11 & 9561 & 9621 & -4769 & $53.2(2)$ & $<0.0001$ \\
\hline
\end{tabular}

Note: Outcome assessed only at T1, T5, and T6 could not be fit to a random slope piecewise model. AIC $=$ Akaike Information Criterion. BIC = Bayesian Information Criterion. LogLik = Log likelihood. Chi-sq $=$ Chi-square test. 


\section{Table S7}

\section{Pattern-Mixture Modeling Sensitivity Analyses Results}

\begin{tabular}{lcccc}
\hline & \multicolumn{5}{c}{ Intention-to-treat sample } \\
Outcome & $10 \%$ worse than MAR & $20 \%$ worse than MAR \\
& $B$ & $p$ & $B$ & $p$ \\
\cline { 2 - 5 } & & & & \\
Psychological distress & -0.40 & $<0.001$ & -0.40 & $<0.001$ \\
T1 to T5 & -0.27 & $<0.001$ & -0.26 & $<0.001$ \\
T1 to T6 & & & & \\
Mindful action & 0.88 & 0.018 & 0.60 & 0.110 \\
T1 to T5 & 0.64 & 0.193 & 0.40 & 0.440 \\
T1 to T6 & & & & \\
Self-compassion & 0.22 & $<0.001$ & 0.18 & $<0.001$ \\
T1 to T5 & 0.14 & 0.015 & 0.11 & 0.067 \\
T1 to T6 & & & & \\
Loneliness & -0.21 & $<0.001$ & -0.19 & $<0.001$ \\
T1 to T5 & -0.21 & 0.001 & -0.19 & 0.005 \\
T1 to T6 & & & & \\
Cognitive defusion & 2.51 & $<0.001$ & 2.20 & $<0.001$ \\
T1 to T5 & 2.19 & 0.003 & 1.89 & 0.010 \\
T1 to T6 & & & & \\
Perseverative thinking & -3.29 & $<0.001$ & -3.07 & $<0.001$ \\
T1 to T5 & -1.80 & 0.051 & -1.57 & 0.097 \\
T1 to T6 & & & & \\
Well-being & 1.52 & $<0.001$ & 1.36 & $<0.001$ \\
T1 to T5 & 1.31 & $<0.001$ & 1.16 & 0.002 \\
T1 to T6 &
\end{tabular}

Note: Models were the same as primary intention-to-treat analyses, fit to each of the 50 imputed, scaled datasets separately and then pooled according to Rubin's rules. 


\section{Table S8}

Pattern-Mixture Modeling Sensitivity Analyses of Adverse Effects

\begin{tabular}{|c|c|c|c|c|}
\hline \multirow{3}{*}{ Outcome } & \multicolumn{4}{|c|}{ Intention-to-treat sample } \\
\hline & \multicolumn{2}{|c|}{$10 \%$ worse than MAR } & \multicolumn{2}{|c|}{$20 \%$ worse than MAR } \\
\hline & Estimate & $p$ & Estimate & $p$ \\
\hline Anxiety symptoms & & & & \\
\hline $\mathrm{T} 1$ to $\mathrm{T} 5$ & -0.65 & $<0.001$ & -0.61 & $<0.001$ \\
\hline $\mathrm{T} 1$ to $\mathrm{T} 6$ & -0.16 & 0.359 & -0.12 & 0.493 \\
\hline $\begin{array}{l}\text { Depressive symptoms } \\
\text { T1 to T5 }\end{array}$ & -0.67 & $<0.001$ & -0.58 & 0.002 \\
\hline T1 to $\mathrm{T} 6$ & -0.40 & 0.023 & -0.31 & 0.080 \\
\hline
\end{tabular}

Note: Anxiety symptoms $=$ a one or more categorical increase in symptoms based on the T-score categories of $<55, \geq 55<60, \geq 60<70$, and $\geq 70$ (none-to-slight, mild, moderate, and severe, respectively). Depressive symptoms $=$ a one or more categorical increase in symptoms based on the T-score categories of $<55, \geq 55<60, \geq 60<70$, and $\geq 70$ (none-to-slight, mild, moderate, and severe, respectively). 


\section{CONSORT 2010 checklist of information to include when reporting a randomised trial*}

\begin{tabular}{|c|c|c|c|}
\hline Section/Topic & $\begin{array}{l}\text { Item } \\
\text { No }\end{array}$ & Checklist item & $\begin{array}{l}\text { Reported } \\
\text { on page No }\end{array}$ \\
\hline \multicolumn{4}{|l|}{ Title and abstract } \\
\hline & $1 \mathrm{a}$ & Identification as a randomised trial in the title & 1 \\
\hline & $1 b$ & Structured summary of trial design, methods, results, and conclusions (for specific guidance see CONSORT for abstracts) & 3 \\
\hline \multicolumn{4}{|l|}{ Introduction } \\
\hline \multirow{2}{*}{$\begin{array}{l}\text { Background and } \\
\text { objectives }\end{array}$} & $2 a$ & Scientific background and explanation of rationale & $5-14$ \\
\hline & $2 b$ & Specific objectives or hypotheses & 14-15 \\
\hline \multicolumn{3}{|l|}{ Methods } & $14-17$ \\
\hline \multirow[t]{2}{*}{ Trial design } & $3 a$ & Description of trial design (such as parallel, factorial) including allocation ratio & 14-11 \\
\hline & $3 b$ & Important changes to methods after trial commencement (such as eligibility criteria), with reasons & NA \\
\hline \multirow[t]{2}{*}{ Participants } & $4 \mathrm{a}$ & Eligibility criteria for participants & 15-16 \\
\hline & $4 b$ & Settings and locations where the data were collected & 17-18 \\
\hline Interventions & 5 & $\begin{array}{l}\text { The interventions for each group with sufficient details to allow replication, including how and when they were } \\
\text { actually administered }\end{array}$ & 18-19 \\
\hline \multirow[t]{2}{*}{ Outcomes } & $6 a$ & $\begin{array}{l}\text { Completely defined pre-specified primary and secondary outcome measures, including how and when they } \\
\text { were assessed }\end{array}$ & $19-23$ \\
\hline & $6 b$ & Any changes to trial outcomes after the trial commenced, with reasons & 26-27 \\
\hline \multirow[t]{2}{*}{ Sample size } & $7 a$ & How sample size was determined & 23-24 \\
\hline & $7 b$ & When applicable, explanation of any interim analyses and stopping guidelines & NA \\
\hline \multicolumn{4}{|c|}{ 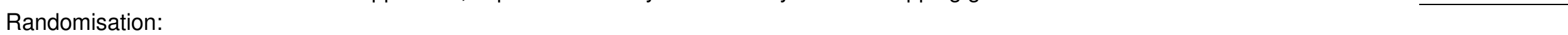 } \\
\hline \multirow{2}{*}{$\begin{array}{l}\text { Sequence } \\
\text { generation }\end{array}$} & $8 a$ & Method used to generate the random allocation sequence & 17 \\
\hline & $8 b$ & Type of randomisation; details of any restriction (such as blocking and block size) & 17 \\
\hline $\begin{array}{l}\text { Allocation } \\
\text { concealment } \\
\text { mechanism }\end{array}$ & 9 & $\begin{array}{l}\text { Mechanism used to implement the random allocation sequence (such as sequentially numbered containers), } \\
\text { describing any steps taken to conceal the sequence until interventions were assigned }\end{array}$ & 17 \\
\hline Implementation & 10 & $\begin{array}{l}\text { Who generated the random allocation sequence, who enrolled participants, and who assigned participants to } \\
\text { interventions }\end{array}$ & 17 \\
\hline Blinding & $11 \mathrm{a}$ & If done, who was blinded after assignment to interventions (for example, participants, care providers, those & 17 \\
\hline
\end{tabular}


assessing outcomes) and how

11b If relevant, description of the similarity of interventions

Statistical methods $12 \mathrm{a}$ Statistical methods used to compare groups for primary and secondary outcomes

$12 \mathrm{~b}$ Methods for additional analyses, such as subgroup analyses and adjusted analyses

NA

24-26

26-27

\section{Results}

Participant flow (a diagram is strongly recommended)

Recruitment

For each group, the numbers of participants who were randomly assigned, received intended treatment, and were analysed for the primary outcome

3b For each group, losses and exclusions after randomisation, together with reasons

14a Dates defining the periods of recruitment and follow-up

14b Why the trial ended or was stopped

15 A table showing baseline demographic and clinical characteristics for each group

\section{Baseline data}

Numbers analysed

For each group, number of participants (denominator) included in each analysis and whether the analysis was by original assigned groups

Outcomes and

estimation For each primary and secondary outcome,
precision (such as $95 \%$ confidence interval)

$17 \mathrm{~b}$ For binary outcomes, presentation of both absolute and relative effect sizes is recommended

18 Results of any other analyses performed, including subgroup analyses and adjusted analyses, distinguishing pre-specified from exploratory

Ancillary analyses

Harms

All important harms or unintended

\section{Discussion}

Limitations

Generalisability

Interpretation

Trial limitations, addressing sources of potential bias, imprecision, and, if relevant, multiplicity of analyses Generalisability (external validity, applicability) of the trial findings

Other information Registration

Protocol

Funding

\section{Registration number and name of trial registry}

24 Where the full trial protocol can be accessed, if available

25 Sources of funding and other support (such as supply of drugs), role of funders

\section{7 \&fig. 2}

27-28 \& Fig 2

\begin{tabular}{l}
\hline 27 \\
\hline NA \\
\hline 51
\end{tabular}

\section{5,27}

28-29

30

30

30

35

35-36

31-36

\section{7}

17

2

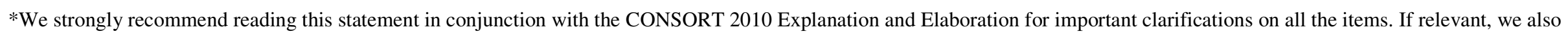

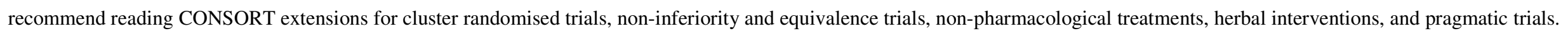
Additional extensions are forthcoming: for those and for up to date references relevant to this checklist, see www.consort-statement.org. 